\title{
Micro-Loans, Insecticide-Treated Bednets, and Malaria: Evidence from a Randomized Controlled Trial in Orissa, India
}

\author{
By Alessandro Tarozzi, Aprajit Mahajan, Brian Blackburn, \\ DAN Kopf, LAKSHMI KRISHNAN, AND JOANNE YOONG*
}

\begin{abstract}
We describe findings from the first large-scale cluster randomized controlled trial in a developing country that evaluates the uptake of a health-protecting technology, insecticide-treated bednets (ITNs), through micro-consumer loans, as compared to free distribution and control conditions. Despite a relatively high price, 52 percent of sample households purchased ITNs, highlighting the role of liquidity constraints in explaining earlier low adoption rates. We find mixed evidence of improvements in malaria indices. We interpret the results and their implications within the debate about cost sharing, sustainability and liquidity constraints in public health initiatives in developing countries. (JEL D12, G21, H51, I12, I18, O15, O18)
\end{abstract}

\footnotetext{
* Tarozzi: Department of Economics and Business, Universitat Pompeu Fabra and Barcelona GSE, Jaume I Building, Ramon Trias Fargas 25-27, 08005 Barcelona, Spain, and Barcelona GSE (e-mail: alessandro.tarozzi@ upf.edu); Mahajan: Economics Department, UCLA, 8283 Bunche Hall, Los Angeles, CA 90095 (e-mail: aprajit@ gmail.com); Blackburn: Division of Infectious Diseases and Geographic Medicine, Stanford University School of Medicine, 300 Pasteur Drive, Lane Building, Room L-136 Stanford, CA 94305 (e-mail: blackburn@ @tanford.edu); Kopf: Research Division, Savvy Sherpa, 6200 Shinglecreek Parkway, Minneapolis, MN 55430 (e-mail: dankopf@ savvysherpa.com); Krishnan: Independent Science and Partnership Council Secretariat of CGIAR, C6/35, FAO, Viale delle Terme di Caracalla, Rome 00153 (e-mail: lakshmi.krishnan@ aya.yale.edu); Yoong: National University of Singapore, Saw Swee Hock School of Public Health, 16 Medical Drive, Block MD3 Singapore 117597, and RAND Corporation (e-mail: joanne_yoong@nuhs.edu.sg). During this project, Kopf and Krishnan were employed by the Institute for Financial Management and Research-Centre for Micro Finance (CMF, Chennai, India). We are grateful to a number of colleagues and institutions. In particular: Khirod Chandra Malick, Dipti Pattnaik, and Asish Sahoo at BISWA, Anup Roy, Benita Sarah Matthew, Deepak Nayak, Projjal Saha, Sudhansu Behera, and all survey monitors; Madan Mohan Pradhan, at the National Vector Borne Diseases Control Programme, Orissa; Annie Duflo and the Center for Micro Finance; Ravi and Saurabh Singhal of Biotech International, and Binax for donating materials. K. S. Sharma and his team at the Malaria Research Centre Field Station in Rourkela; the Dwight Mount Division of Parasitic Diseases, Centers for Disease Control and Prevention; the Center for Micro Finance, the Stanford Presidential Fund for Innovation in International Studies, the Stanford Center for International Development, the Stanford OTL Research Incentive Fund, RAND Corporation, and the Duke Arts and Sciences Committee on Faculty Research for financial support; Jason Blevins, Patricia Foo, and Kristin Johnson for outstanding research assistance; James Berry, Pascaline Dupas, Seema Jayachandran, Leigh Linden, Andrea Locatelli, Grant Miller, Wendy Prudhomme O'Meara, Elisa Sicuri, Duncan Thomas, Paul Wise, many participants to seminars and conferences, and especially anonymous referees for constructive comments. This study was partially funded by the National Institute of Allergy and Infectious Diseases R03AI078119 and by the Marie Curie International Incoming Fellowship FP7-PEOPLE-2011-IXF, Proposal ID 298904. This study received IRB approvals from Duke University (protocol \#9447-07), Stanford University (8149), the Indian Council of Medical Research (TDR/507/2008-ECD-II), UPF (2011/4543/I), the Institute for Financial Management and Research (Chennai, India) and the Independent Ethics Committee (Mumbai, India).

${ }^{\dagger}$ Go to http://dx.doi.org/10.1257/aer.104.7.1909 to visit the article page for additional materials and author disclosure statement(s).
} 
A number of recent empirical studies have demonstrated that without free distribution or substantial subsidies, the adoption of highly beneficial health-protecting technologies remains very low among the poor in developing countries. Demand has been shown to be remarkably price-elastic, with even small levels of cost-sharing leading to huge declines in adoption. In Kenya, Kremer and Miguel (2007) found that a 20 percent co-pay for drugs to eliminate intestinal worms reduced uptake from 75 to 19 percent. In urban Zambia, Ashraf, Berry, and Shapiro (2010) estimated a price elasticity of -0.6 for the demand of a relatively inexpensive water disinfectant, effective for the prevention of waterborne diseases that are especially dangerous to young children. Kremer et al. (2009) documented only a 10 percent uptake when a similar product was offered at half-price in Kenya. In rural Kenya, Cohen and Dupas (2010) found that a remarkable 90 percent subsidy reduced adoption of insecticide treated bednets to 10 percent, relative to 99 percent achieved with free distribution. In rural Zambia, subsidization did not increase bednet ownership rates among the poorest households (Agha et al. 2007).

Liquidity constraints have been hypothesized to be a key reason for such low adoption rates, because several health products require investing sums that may be non-negligible for poor households (Dupas 2011). Free provision or heavy subsidization are thus being advocated by some quarters, especially in the presence of externalities in adoption such as in the case of insecticide treated nets (World Health Organization 2007) or de-worming drugs (Kremer and Miguel 2007).1 However, budget constraints often impose serious limits on the ability of public health campaigns to protect all those at risk. In addition, there has been much recent debate on the sustainability of development initiatives, with advocates citing cost-recovery as a crucial criterion for evaluating poverty reduction, health, and education programs (Alam and Ahmed 2010; Sarriot, Swedberg, and Ricca 2011; Smith 2010). Cost-sharing may also help targeting subsidies toward users with higher marginal benefits, although liquidity constraints will limit such objectives if those at risk are also less able to pay.

When heavy subsidization is not possible but liquidity constraints are a key determinant of low demand, micro-loans may offer a promising option in the search for sustainable public health initiatives. This paper describes findings from the first large-scale cluster randomized controlled trial (RCT) in a developing country context that evaluates the adoption and health impacts of a health-protecting technology offered with micro-consumer loans, relative to free distribution or control conditions. Specifically, we evaluate the effectiveness of micro-loans at increasing ownership and use of insecticide treated bednets (ITNs), and ultimately at reducing the burden of malaria in areas of rural Orissa (India) where the disease is endemic.

Transmitted by Anopheles mosquitoes, malaria represents an enormous global health burden, with a worldwide incidence of 300-660 million cases annually, 80 million in India alone. ${ }^{2}$ One third of the human population is estimated to live in areas at risk for the most severe form of malaria, caused by Plasmodium

\footnotetext{
${ }^{1}$ See, e.g., Hammer (1997) and Gersovitz and Hammer $(2004,2005)$ for an examination of economic approaches toward health and infectious diseases in particular.

${ }^{2}$ See Snow et al. (2005) and Korenromp (2005). For a comprehensive survey of the disease, including its epidemiology, pathology, and treatment, see White (2009).
} 
falciparum (Snow et al. 2005). The negative association between the disease and economic growth and the accumulation of human capital has been long recognized, although studies that convincingly document and quantify causal links are relatively recent within the economics literature. ${ }^{3}$ Numerous randomized trials have shown that with high coverage and/or high usage rates ITNs are efficacious at reducing malaria-related morbidity and mortality, as documented in the extensive survey in Lengeler (2004). However, ITN adoption in most malarious areas remains very low and public health agencies frequently have insufficient resources to provide universal ITN coverage. In such a context, a more sustainable approach focusing on cost-recovery may be desirable, but it may lead to the exclusion of vulnerable individuals who do not have access to sufficient funds.

Our field experiment was conducted in 141 villages in rural Orissa, in collaboration with BISWA (Bharat Integrated Social Welfare Agency), a micro-lender with a large presence in the state. After a baseline household survey, completed in the spring of 2007, we randomly assigned villages to three equally sized groups. A control group received no further interventions, while lender clients in a second group received at no cost a number of ITNs depending on household composition. Clients from the third group were offered contracts for the purchase of ITNs and re-treatments, using consumer loans with a one-year repayment period. The ITN offer price was not subsidized and included a mark-up to cover delivery and overhead costs to BISWA. The price was not negligible, corresponding approximately to 3-5 times the local daily agricultural wage.

This paper has two specific aims. First, we evaluated to what extent the offer of small loans for purchasing ITNs led to increases in ownership, even among poor households. To the best of our knowledge, this is the first large-scale cluster RCT to evaluate the efficacy of a public health program where a health-protecting technology was provided at full cost but allowing for repayment over time, as compared to both control conditions or free distribution. Fink and Masiye (2012) describe the result of a later study in Zambia, where bednets were offered on credit to farmers with access to agricultural loans. Devoto et al. (2012) study adoption of piped water contracts offered on credit in urban Morocco, but focus on how information and counseling affected loan applications open to all study subjects. We also evaluate the cost-effectiveness of micro-loans when compared to free distribution, taking into account that we observed partial repayment rates. In order to further gauge the role of liquidity constraints as a barrier to demand, we also studied uptake of ITNs offered for cash, although this intervention was conducted at a later time.

Second, we evaluated the impact of the alternative ITN delivery mechanisms on different malaria indicators. Our data include results from thousands of blood tests that allow us to estimate changes in malaria prevalence (the fraction of infected individuals at a given point in time) as well as in hemoglobin levels. We also study changes in malaria incidence (the number of illness episodes over a period of time), although these were respondent-reported. The impact of ITNs distributed free of cost on malaria indices has been studied extensively, although all but one of the 22 studies reviewed in Lengeler (2004) were "efficacy" trials, that is, conducted

\footnotetext{
${ }^{3}$ See Gallup and Sachs (2001); Sachs and Malaney (2002); Malaney, Spielman, and Sachs (2004); Hong (2007a); Hong (2007b); Barreca (2010); Bleakley (2010); Cutler et al. (2010); Lucas (2010); and Kitchens (2013).
} 
under highly controlled conditions generally leading to high coverage and use rates. In contrast, our study could be seen as an "effectiveness" trial, carried out on a large scale and without potentially invasive surveillance of malaria indices and ITN usage. In addition, our program did not seek universal community-level coverage but only targeted BISWA-affiliated households. This led to low coverage, a condition that may be important for public health interventions where externalities are present. Ours is also the first large-scale RCT that analyzes the impact of ITNs on malaria indices in India. ${ }^{4}$

The rest of the paper is organized as follows. Section I describes the study area, the RCT design, and the data. Section II describes the impacts on ITN adoption and (self-reported) usage and examines the role of liquidity constraints on demand for ITN. Section III discusses the impacts on malaria indices as measured both through blood tests and recall data, after clarifying the features of each indicator and their interrelationship. This section also discusses the findings in light of the epidemiological and public health literature on the impact of ITNs on malaria indices. Section IV briefly considers cost-effectiveness of free ITN provision versus sales on credit. Finally, Section V summarizes and interprets the results and highlights limitations. Because of space constraints, we will refer the reader to the online Appendix for a number of details and additional results.

\section{Location, Study Design, and Data}

This study was carried out in 141 villages from five districts in rural Orissa, the most highly malaria-endemic state in India (Kumar et al. 2007), and conducted in collaboration with BISWA, a micro-lender with a large local presence. Study locations were selected by stratified random sampling from a list of 878 villages with BISWA presence..$^{5}$ A pre-intervention baseline survey was completed in May-June 2007 for a random sample of 1,844 households. Within each village, 15 households were randomly selected from all those with preexisting BISWA accounts as of November 2006, regardless of whether they had an active loan at that time (all were selected if fewer than 15 were present in the BISWA rosters).

Two key malaria indicators (malaria prevalence and hemoglobin levels, $\mathrm{Hb}$ ) were measured with rapid diagnostic tests (RDTs), and the results were immediately communicated to the subjects. These tests require very small blood samples and deliver results within minutes (see online Appendix A.2 for details). Individuals targeted for blood tests included all pregnant women, children under the age of five (U5) and their mothers, and one randomly selected adult (age 15-60). The malaria RDT detects current or recent infections accurately (up to 2-4 weeks prior to the test), but does not indicate the level of parasitemia. The test can also distinguish infections due to different Plasmodium species, but because almost all infections in our sample were due to the most severe form of malaria (caused by P. falciparum), we only present pooled results. Malaria prevalence is thus a cross-sectional estimate

\footnotetext{
${ }^{4} \mathrm{~A}$ number of studies have been conducted in Orissa and elsewhere in India but they lack an appropriate control group and/or have insufficient sample size, see Lengeler (2004, p. 16) for references.

${ }^{5}$ Online Appendix A.1 includes the details of the sample selection, and documents how study villages were on average larger and with better amenities than the overall population of villages in the five districts.
} 
of the fraction of tested individuals with the illness at a given point in time. Anemia, defined here as $\mathrm{Hb}$ levels below 11 grams per deciliter of blood, is a common health condition in developing countries and can be severely worsened by Malaria (White 2009). A significant change in anemia rates in U5 is often one of the most sensitive indicators of changes in malaria incidence (Hawley et al. 2003, ter Kuile et al. 2003). For each individual we also recorded respondent-diagnosed illness episodes during the previous six months, which allows us to construct measures of malaria incidence during the period. Unlike prevalence, this index is a "flow" variable that measures the overall burden of disease in the study population over a period of time. In Section III we discuss at length the relative merit of these two indicators as well as their relationship in epidemiological models of malaria transmission.

After the completion of the baseline, the 141 villages were randomly assigned to three study groups of 47 villages each. We label the three arms (described in detail later) as "MF" (microfinance), when nets were offered for sale on credit, "Free," when the intervention called for free distribution of ITNs, and "Control" when neither intervention was introduced. In Table 1, we report selected summary statistics from the baseline, together with tests for balance across treatment groups. The null of equality of means across arms is not rejected at standard significance levels in 20 of 23 variables, suggesting overall good inter-arm balance, although there are exceptions that we discuss below.

Average total expenditure was low, about 1.5 USD per person per day in purchasing power parity terms, and approximately 20 percent of households were below the official poverty line for rural Orissa (see the Table 1 notes for details). Despite all sample households being affiliated with BISWA, more than half said they would find it difficult or impossible to borrow Rs 500, which is approximately the price of two program ITNs (see below). Two-thirds of households had at least one net, 95 percent of which had been purchased from the market. The mean (median) price paid was Rs 79 (60). The number of treated nets owned was significantly lower, ranging from 0.02 ITNs per head in Control areas to about 0.05 in Free and MF villages. Despite the low ownership rates in all three arms, the null of equality is rejected at the 5 percent level. More than 10 percent of tested individuals resulted positive for malaria, while more than half were anemic. ${ }^{6}$ Malaria prevalence was marginally higher in treatment areas, 11.5 percent in MF and 12.3 percent in Free, versus 10.8 percent in Control villages, although the differences are not significant $(p$-value $=0.838)$. Self-reported malaria incidence was also higher in MF and Free areas (0.12 episodes per person in the previous six months) relative to Control (0.09), and in this case the null of equality is rejected at the 5 percent level. Estimated malaria-related health expenditures were similarly higher in treatment areas, although the null of equality is not rejected at standard levels (see table notes for details about the estimation of the malaria costs). Overall, these estimates document the poor health status of the study population and suggest potentially large health gains from a reduction in the malaria burden.

In September-October 2007 we revisited the study villages and carried out a public information campaign (IC), after gathering all BISWA members in a village.

\footnotetext{
${ }^{6}$ Malaria prevalence was similar across genders and age groups, while $\mathrm{Hb}$ levels vary widely by age and gender (a common finding in developing countries), see online Appendix A.3 for details.
} 
Table 1-Baseline Summary Statistics and Randomization Tests

\begin{tabular}{|c|c|c|c|c|c|c|}
\hline & $\begin{array}{l}\text { Control } \\
\text { (1) }\end{array}$ & $\begin{array}{l}\text { Free } \\
(2)\end{array}$ & $\begin{array}{l}\text { MF } \\
(3)\end{array}$ & $\begin{array}{c}p \text {-value } \\
(4)\end{array}$ & $\begin{array}{l}\mathrm{SD} \\
(5)\end{array}$ & $\begin{array}{c}\text { Observations } \\
\text { (6) }\end{array}$ \\
\hline $\begin{array}{l}\text { 1. Scheduled caste/tribe/other backward } \\
\text { castes }\end{array}$ & $\begin{array}{l}0.9 \\
(0.013)\end{array}$ & $\begin{array}{c}0.933 \\
(0.013)\end{array}$ & $\begin{array}{c}0.912 \\
(0.021)\end{array}$ & 0.421 & 0.256 & 1,838 \\
\hline 2. Household size & $\begin{array}{l}5.5 \\
(0.103)\end{array}$ & $\begin{array}{c}5.6 \\
(0.117)\end{array}$ & $\begin{array}{l}5.3 \\
(0.086)\end{array}$ & 0.138 & 2.22 & 1,844 \\
\hline 3. Children U5 in household & $\begin{array}{c}0.499 \\
(0.033)\end{array}$ & $\begin{array}{c}0.506 \\
(0.030)\end{array}$ & $\begin{array}{c}0.487 \\
(0.026)\end{array}$ & 0.892 & 0.704 & 1,844 \\
\hline 4. Male household head & $\begin{array}{c}0.952 \\
(0.009)\end{array}$ & $\begin{array}{c}0.941 \\
(0.011)\end{array}$ & $\begin{array}{c}0.932 \\
(0.010)\end{array}$ & 0.368 & 0.235 & 1,843 \\
\hline 5. Household head has some schooling & $\begin{array}{l}0.72 \\
(0.018)\end{array}$ & $\begin{array}{c}0.706 \\
(0.027)\end{array}$ & $\begin{array}{c}0.714 \\
(0.021)\end{array}$ & 0.908 & 0.452 & 1,843 \\
\hline $\begin{array}{l}\text { 6. Household head has secondary } \\
\text { education or above }\end{array}$ & $\begin{array}{c}0.084 \\
(0.016)\end{array}$ & $\begin{array}{c}0.075 \\
(0.013)\end{array}$ & $\begin{array}{c}0.114 \\
(0.015)\end{array}$ & 0.123 & 0.287 & 1,809 \\
\hline $\begin{array}{l}\text { 7. Expenditure per head } \\
(2007 \text { Rs per day })^{\dagger}\end{array}$ & $\begin{array}{l}22.3 \\
(0.928)\end{array}$ & $\begin{array}{l}21.2 \\
(0.827)\end{array}$ & $\begin{array}{l}24.2 \\
(1.101)\end{array}$ & $0.085^{*}$ & 16.2 & 1,844 \\
\hline $\begin{array}{l}\text { 8. Poor }(\text { expenditure per head }<\text { official } \\
\text { poverty line) })^{\dagger \dagger}\end{array}$ & $\begin{array}{c}0.195 \\
(0.025)\end{array}$ & $\begin{array}{l}0.24 \\
(0.031)\end{array}$ & $\begin{array}{c}0.196 \\
(0.024)\end{array}$ & 0.463 & 0.408 & 1,844 \\
\hline $\begin{array}{l}\text { 9. Difficult/impossible for household } \\
\text { to borrow Rs } 500\end{array}$ & $\begin{array}{c}0.529 \\
(0.026)\end{array}$ & $\begin{array}{c}0.536 \\
(0.029)\end{array}$ & $\begin{array}{c}0.529 \\
(0.025)\end{array}$ & 0.980 & 0.499 & 1,842 \\
\hline 10. Ratio debt/total yearly expenditure & $\begin{array}{l}0.47 \\
(0.082)\end{array}$ & $\begin{array}{c}0.389 \\
(0.048)\end{array}$ & $\begin{array}{c}0.400 \\
(0.040)\end{array}$ & 0.685 & 1.01 & 1,843 \\
\hline 11. Household has at least one net & $\begin{array}{c}0.654 \\
(0.030)\end{array}$ & $\begin{array}{c}0.628 \\
(0.029)\end{array}$ & $\begin{array}{c}0.68 \\
(0.023)\end{array}$ & 0.373 & 0.476 & 1,844 \\
\hline 12. Nets (per capita) ${ }^{\dagger}$ & $\begin{array}{c}0.287 \\
(0.020)\end{array}$ & $\begin{array}{c}0.264 \\
(0.018)\end{array}$ & $\begin{array}{c}0.311 \\
(0.018)\end{array}$ & 0.167 & 0.3 & 1,836 \\
\hline 13. ITNs (per capita) $)^{\dagger}$ & $\begin{array}{c}0.021 \\
(0.006)\end{array}$ & $\begin{array}{c}0.046 \\
(0.013)\end{array}$ & $\begin{array}{c}0.055 \\
(0.014)\end{array}$ & $0.027 * *$ & 0.146 & 1,831 \\
\hline $\begin{array}{l}\text { 14. Expenditure for self-diagnosed malaria } \\
\text { last } 6 \text { months* }\end{array}$ & $\begin{array}{l}565 \\
(77)\end{array}$ & $\begin{array}{l}725 \\
(72)\end{array}$ & $\begin{array}{l}686 \\
(85)\end{array}$ & 0.298 & 1,689 & 1,844 \\
\hline 15. Used net last night ${ }^{\dagger}$ & $\begin{array}{c}0.131 \\
(0.022)\end{array}$ & $\begin{array}{c}0.116 \\
(0.019)\end{array}$ & $\begin{array}{c}0.162 \\
(0.017)\end{array}$ & 0.195 & 0.295 & 1,844 \\
\hline 16. Used ITN last night ${ }^{\dagger}$ & $\begin{array}{c}0.019 \\
(0.006)\end{array}$ & $\begin{array}{c}0.022 \\
(0.007)\end{array}$ & $\begin{array}{l}0.03 \\
(0.010)\end{array}$ & 0.617 & 0.134 & 1,840 \\
\hline $\begin{array}{l}\text { 17. Use regularly nets during } \\
\text { "mosquito season" }\end{array}$ & $\begin{array}{c}0.564 \\
(0.032)\end{array}$ & $\begin{array}{c}0.512 \\
(0.030)\end{array}$ & $\begin{array}{c}0.572 \\
(0.028)\end{array}$ & 0.304 & 0.453 & 1,844 \\
\hline
\end{tabular}

(Continued)

The IC included a brief presentation about malaria and its transmission, the importance of ITN use, a demonstration of how to hang and use nets properly, and advice on re-treatment. In treatment communities, the IC also included an explanation of the intervention to be rolled out.

In the 47 Free villages, all households with at least one BISWA member (regardless of inclusion in our baseline sample) received a number of free nets as a function of family composition, up to a maximum of four. The nets were of very good quality and significantly sturdier than most of the preexisting ones. They were treated with deltamethrin, an insecticide demonstrated to be effective against Anopheles mosquitoes in Orissa. Nets were treated on the spot by trained personnel..$^{7}$ Individuals were also

\footnotetext{
${ }^{7}$ See online Appendix A.4 for specifics about bednets, insecticide, and the treatment procedure.
} 
Table 1-Baseline Summary Statistics and Randomization Tests (Continued)

\begin{tabular}{|c|c|c|c|c|c|c|}
\hline & $\begin{array}{l}\text { Control } \\
\text { (1) }\end{array}$ & $\begin{array}{l}\text { Free } \\
(2)\end{array}$ & $\begin{array}{l}\text { MF } \\
(3)\end{array}$ & $\begin{array}{c}p \text {-value } \\
\text { (4) }\end{array}$ & $\begin{array}{l}\text { SD } \\
(5)\end{array}$ & $\begin{array}{c}\text { Observations } \\
\text { (6) }\end{array}$ \\
\hline 18. Price paid for bednets $(2007 \mathrm{Rs})^{+}$ & $\begin{array}{l}82.9 \\
(8.2)\end{array}$ & $\begin{array}{l}83.5 \\
(8.4)\end{array}$ & $\begin{array}{l}72.9 \\
(6.6)\end{array}$ & 0.510 & 63 & 579 \\
\hline 19. Malaria prevalence (RDT) & $\begin{array}{c}0.108 \\
(0.016)\end{array}$ & $\begin{array}{c}0.115 \\
(0.018)\end{array}$ & $\begin{array}{c}0.123 \\
(0.018)\end{array}$ & 0.838 & 0.32 & 2,557 \\
\hline 20. Hemoglobin (RDT) & $\begin{array}{l}11.0 \\
(0.087)\end{array}$ & $\begin{array}{l}10.7 \\
(0.096)\end{array}$ & $\begin{array}{l}11.0 \\
(0.087)\end{array}$ & 0.132 & 1.91 & 2,528 \\
\hline $\begin{array}{l}\text { 21. Anemia prevalence }(\mathrm{Hb}<11 \mathrm{~g} / \mathrm{dl}) \\
\text { (RDT) }\end{array}$ & $\begin{array}{c}0.527 \\
(0.024)\end{array}$ & $\begin{array}{c}0.569 \\
(0.025)\end{array}$ & $\begin{array}{c}0.504 \\
(0.020)\end{array}$ & 0.121 & 0.499 & 2,528 \\
\hline $\begin{array}{l}\text { 22. Self-diagnosed malaria episodes } \\
\text { last } 6 \text { months }\end{array}$ & $\begin{array}{c}0.093 \\
(0.009)\end{array}$ & $\begin{array}{c}0.124 \\
(0.012)\end{array}$ & $\begin{array}{c}0.125 \\
(0.012)\end{array}$ & $0.045^{* *}$ & 0.328 & 10,062 \\
\hline $\begin{array}{l}\text { 23. Self-diagnosed malaria/fever episodes } \\
\text { last } 6 \text { months }\end{array}$ & $\begin{array}{c}0.218 \\
(0.015)\end{array}$ & $\begin{array}{c}0.238 \\
(0.015)\end{array}$ & $\begin{array}{c}0.258 \\
(0.017)\end{array}$ & 0.196 & 0.446 & 10,062 \\
\hline
\end{tabular}

Notes: For each variable, columns 1-3 show the experimental arm-specific means and the corresponding standard errors (in parentheses) adjusted for intra-village correlation. Column 4 reports $p$-values for a test of the null hypothesis that the means are identical across the three experimental arms. Column 5 contains the standard deviation of the variable calculated over the whole sample and column 6 indicates the number of non-missing observations. The unit of observation of the variables is the household in rows $1-17$, a bednet in row 18 and an individual in rows 19-23. The results in rows 19-21 include only information from individuals for whom RDTs were conducted. The means for variables denoted ${ }^{\dagger}$ were weighted by household size. ${ }^{+}$Mean bednet prices are estimated as arm-specific means of prices paid for bednets owned by households at baseline, imputing a zero if the net had been received free of charge. ${ }^{*}$ For each malaria episode, we noted all the related monetary costs as well as the number of days of work or school lost. Health expenditures were elicited using an itemized list that included doctor fees, drugs and tests, hospitalization, surgery, costs of lodging and transportation (including those for any caretaker), lost earnings from days of lost work, and cost of non-household members hired to replace the sick at work. "Poor" is a dummy equal to one if per capita monthly household expenditure is below a poverty line equal to Rs $381=326$ $\times(373 / 319.5)$, where 326 is the official poverty line for rural Orissa in 2004-2005, and 373 and 319.5 are the Consumer Price Index for Agricultural Laborers in May-June 2007 and July 2004-June 2005 respectively. According to the 2005 International Comparison Group Global Report, the purchasing power parity exchange rate was Rs 14.67 per 1 USD, see http://siteresources.worldbank.org/ICPINT/Resources/icp-final-tables.pdf.

*** Significant at the 1 percent level.

** Significant at the 5 percent level.

* Significant at the 10 percent level.

Source: Data from 1,844 households included in the pre-intervention household survey (April-May 2007).

informed that our team would return after six and twelve months to re-treat the nets at no cost.

In MF communities, ITNs were offered through micro-loan contracts and, as in Free communities, only BISWA clients were targeted. ITNs could also be purchased for cash. The micro-consumer loans were offered by BISWA separately and in addition to any other loan already outstanding. There was no movement of funds at the time of purchase: if a household decided to buy ITNs, these were delivered after being treated as described above and repayment was scheduled to be completed within one year. Field workers clarified that default on ITN loans would be treated similarly to defaults for other BISWA loans and that purchase decisions would not affect their access to regular BISWA loans beyond that determined by repayment behavior.

ITN distribution and recording of loan contracts were to be completed 2-3 days after the IC. ${ }^{8}$ The time interval between the IC and the purchase decision was

\footnotetext{
${ }^{8}$ In reality, loan management was not carried out uniformly across the study areas by BISWA personnel.
} 
introduced to ensure that the households had an opportunity to consider the offer carefully. A second visit was conducted approximately one month later, where ITNs were offered again with the same contracts. No ITNs were offered after this second visit.

ITNs were offered for sale with two alternative loan contracts, both at BISWA's standard interest rate, 20 percent per year. The two contracts allowed buyers to choose between the purchase of an ITN, or (for a higher price) a bundle which also included two re-treatments to be completed at no additional cost six and 12 months later. The price of nets ranged from 173 to 259 rupees, depending on contract choice or net size (single or double). For perspective, at the time of the intervention daily wages for agricultural labor were around Rs 50, and one kilogram of rice cost approximately Rs 10. Our project team re-visited MF and Free villages in March-April and September-October 2008 for the re-treatment of the bednets, which was completed by study personnel in a central location within villages. Re-treatment was offered at no additional cost, except for buyers who did not choose the bundled contract in MF areas who were offered re-treatment for cash, at Rs 15 (18) per single (double) net. ${ }^{9}$

A detailed post-intervention survey was conducted shortly after the second retreatment, between December 2008 and April 2009. The content of the survey instrument was similar to the baseline questionnaire and again measured ITN ownership and usage, and health status. Malaria prevalence and $\mathrm{Hb}$ levels were measured by similar methodology to the baseline survey. A longitudinal dataset was created by recontacting all baseline households whenever possible. Additional funding also enabled us to increase the number of biomarkers collected by attempting to test all household members for malaria and $\mathrm{Hb}$, rather than only specific demographic groups as at baseline.

Attrition at follow-up was limited and mostly due to temporary migration or inability to find respondents despite repeated visits. Of the 1,844 initial households, 1,768 (96 percent) were reinterviewed. The null of equal attrition rates among arms is not rejected at standard levels, and neither bednet ownership nor the results of the biomarkers at baseline are statistically or substantively significant predictors of attrition (see online Appendix A.5 for details).

In describing the impacts of the interventions, we rely on intent-to-treat (ITT) estimates, that is, we focus on post-intervention differences in outcomes between experimental arms regardless of actual program uptake. We estimate all regressions using ordinary least squares (OLS), with statistical inference robust to intra-village correlation of residuals.

\section{Impacts on ITN Ownership and Usage}

We first evaluate the impact of the intervention on ITN uptake, ownership, and usage. In communities with free distribution, almost all sample households (96 percent) received at least one ITN, with an average of 2.7 nets per household, about one every two people (Table 2, columns 1 and 2). In MF villages, ITN acquisition was

\footnotetext{
${ }^{9}$ Because of space constraints, in this paper we ignore the contract choice. Tarozzi et al. (2011) show that, as expected, re-treatment rates were significantly lower among buyers who choose to purchase the ITNs without the two re-treatments included in the price.
} 
substantively and statistically significantly lower, with 309 of 589 sample households (52 percent) purchasing at least one ITN (1.2 nets per household, or one ITN every four people). We also find considerable heterogeneity in purchase rates across villages, with no uptake among sample households in five communities. Almost all buyers chose to purchase on credit, with only ten choosing to pay in cash. Despite the gap relative to free distribution, the 52 percent purchase rate was remarkable, given the nontrivial cost of the ITNs. The high uptake contrasts sharply with the very low cash purchase rates for health products documented among poor households in earlier studies such as Cohen and Dupas (2010). ${ }^{10}$ In Section IIB we discuss the findings from an additional study where we show that in a comparable set of BISWA communities demand for bednets offered only for cash was very low and highly elastic with respect to price.

Next, we assess the change in overall bednet ownership (regardless of acquisition mode or treatment status of the nets) between the baseline and the follow-up survey. Column 3 of Table 2 shows the results of a differences-in-differences (DD) model where the dependent variable is the change in the number of bednets owned by the household, and the regressors are an intercept and dummies for households in MF and Free communities. We observe an increase of 0.3 bednets per household in Control areas but, consistent with the results on ITN uptake, the overall increase was three times as large in MF communities, and six times as large with free distribution. ${ }^{11}$ Free distribution led to a coverage of 0.63 nets per person, which is close to the figure of two nets every three persons which has been taken to represent full coverage in some contexts (see for instance ter Kuile et al. 2003).

The increase in net ownership in intervention areas was lower than the number of nets delivered. The gap was on average 0.8 nets in Free and 0.3 nets in MF. In the latter communities, the average gap is reduced to 0.1 if we exclude two outlier villages where a number of BISWA members purchased more than 15 ITNs each for resale purposes. If we exclude these two villages, in both Free and MF areas there was a 0.2 reduction in BISWA-provided ITNs relative to the time of the intervention (results not shown). These ITNs had been sold or otherwise lost or disposed of. In MF villages (again, excluding the two outliers), we also observe a 0.1 increase in nets purchased from sources other than BISWA. Conversely, in Free villages the additional 0.6 gap is explained by a decline in the number of non-BISWA nets. This is consistent with the hypothesis that older, worn out nets had been disposed of and replaced by the new high-quality ITNs distributed by our program.

Overall, we find that a large majority of ITNs distributed through the program were retained. In addition, the surveyors were instructed to ask permission to see all nets that the respondent listed as being owned by the household, and the presence of 90 percent of the nets was confirmed in this way.

Information on bednet usage also confirmed large increases in intervention communities relative to controls. Both at baseline and follow-up, we recorded whether

\footnotetext{
${ }^{10}$ Note also that the highest offer price for long-lasting ITNs in Cohen and Dupas (2010) was \$1.35 (using PPP conversion rates), that is, just above 10 percent of the least expensive ITN offered in our intervention. At this low price, they estimate a purchase rate of approximately 40 percent.

${ }^{11}$ Tarozzi et al. (2011) also includes, for all outcomes, the results of all regressions estimated in levels using only information from the follow-up survey. Because observed characteristics were overall balanced across arms, these estimates are always very similar and we do not report them for brevity.
} 
TABle 2-Bednet AcQuisition AND OwnershiP

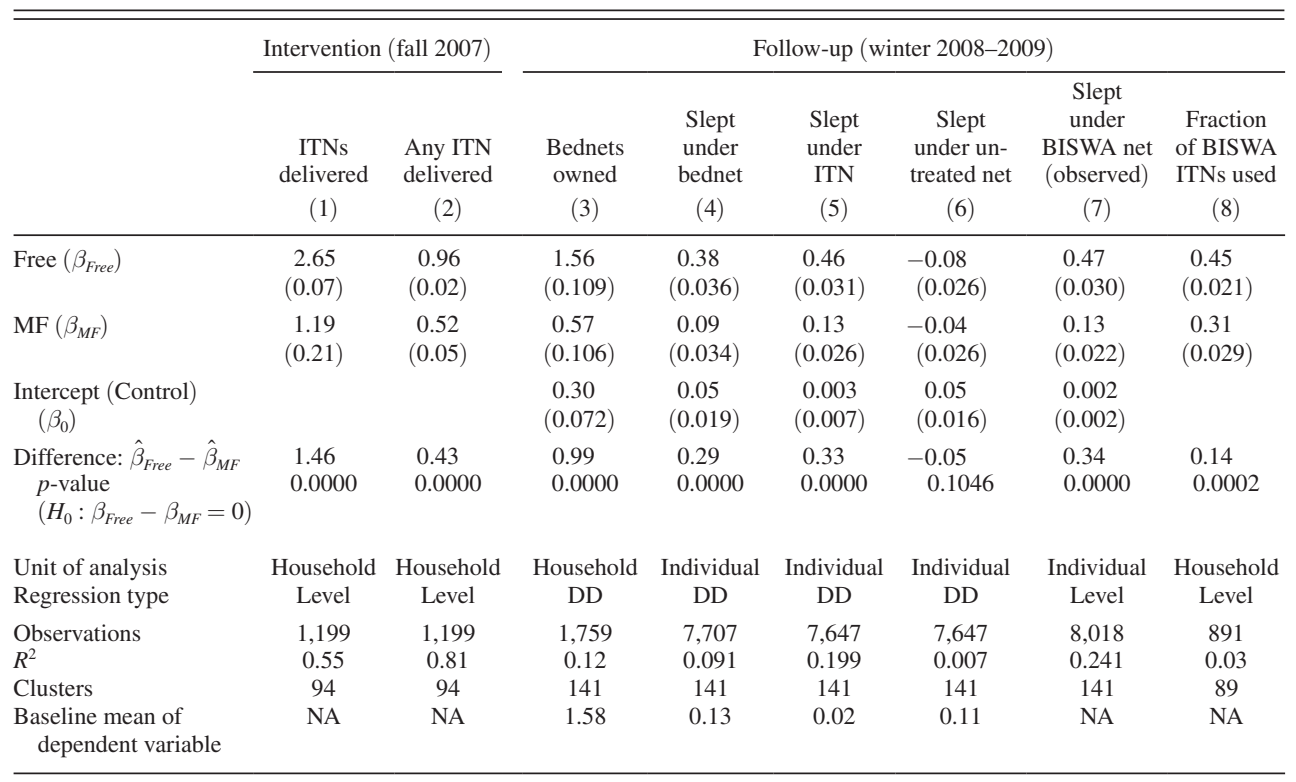

Notes: Standard errors (in parentheses) are robust to intra-village correlation. All regressions estimated with OLS. In columns 1, 2 , and 8 the estimated model is $y=\beta_{M F} M F+\beta_{\text {Free }}$ Free $+u$, where $y$ is the dependent variable, and $M F$ and Free are dummies for the two experimental arms. These regressions use only observations from Free and MF villages. In columns 3 to 7 , the model is $y=$ $\beta_{0}+\beta_{M F} M F+\beta_{\text {Free }}$ Free $+u$, so that $\beta_{M F}$ and $\beta_{\text {Free }}$ are differences relative to controls. The row labeled "regression type" indicates whether $y$ is the level of the variable indicated in the column header or its change between baseline and follow-up survey. In column 7 , the dependent variable is a dummy equal to one when an individual was reported as having used a treated net the night before the interview, and when the net had been observed by the surveyor and identified as one distributed through our program. In column 8 , the dependent variable is the household-specific ratio between the number of BISWA ITNs in use the night before the survey and the number of BISWA ITNs delivered to the household during the intervention. This last regression is thus only estimated including households that received at least one ITN.

household members slept under a bednet the night before the interview, and whether the net had been treated in the previous six months. In Control areas, the proportion of members who slept under a bednet changed from 13 to 18 percent, an increase likely due to the follow-up survey being completed during a period of more intense mosquito activity (column 4 of Table 2). The usage rate increased by an additional 9 percentage points (pp) in $\mathrm{MF}$ and $38 \mathrm{pp}$ in Free communities. Two interesting patterns emerge when we look separately at changes of treated and untreated nets (column 5 and 6). First, there was no increase in ITN usage rates in Control areas, which signals the absence of any cross-arm contamination due to imperfect implementation of the study design or to the presence of other ITN distribution programs in the area. Second, we find again evidence that the new, good quality ITNs supplied by our program displaced nontreated nets, especially in areas with free distribution, where the fraction of members who used an untreated net decreased by 8 pp relative to Control (the decline is significant at the 1 percent level). ${ }^{12}$

\footnotetext{
${ }^{12}$ We also collected information on "regular" usage during the peak mosquito season. The seasonality of malaria transmission has been documented in neighboring areas (Sahu et al. 2003; Sharma et al. 2006). Regular usage rates are substantially higher than previous-night usage, but the cross-arm gradient is similar. The results, omitted for brevity, are available in Tarozzi et al. (2011), where we also document that changes in usage were very similar between genders, but larger for younger individuals, especially in Free areas.
} 
Bednet usage during the previous night and the actual presence of the net in the dwelling were also recorded independently in a census of sleeping spaces. Surveyors listed all sleeping spaces used by the household (including outdoors), recorded which members slept there the previous night, asked whether the space was protected by a net, and noted down the source and price of the net and of any recent re-treatment. Surveyors asked to see all nets reported as having been used. We use these alternative data to construct a new dummy for previous-night usage of a treated net, and one for whether the net had been observed by the surveyor and recognized as an ITN distributed through our program. The results are virtually identical to the earlier ones, and while it is possible that misreporting was common to both sets of responses, the remarkable degree of consistency across sections makes it unlikely. ${ }^{13}$ Even though previous-night usage rates are likely a noisy indicator of consistent usage, the results discussed so far show that the intervention increased ITN adoption substantially, but that free distribution was much more successful than micro-loans at doing so.

A related question is whether the price of ITNs sold on credit generated a screening effect, defined (as in Ashraf, Berry, and Shapiro 2010) as higher usage rates conditional on ownership, relative to what observed with free distribution. This form of screening is often used as an argument in favor of cost-sharing. Ashraf, Berry, and Shapiro (2010) find that households who agreed to purchase a water purification product at higher prices were more likely to use the product, at least in the short term, while Cohen and Dupas (2010) cannot reject the null that women who received free ITNs were as likely to use them as others who paid subsidized but positive prices. In contrast, we find that while in MF areas 31 percent of ITNs had been used the night before, the fraction was 14 pp higher in Free villages, and the difference is statistically significant at any standard level, see column 8 of Table 2.

\section{A. Correlates of ITN Purchases on Credit}

In Table 3, we look at correlates of ITN purchases in MF villages. While these results are descriptive and do not imply causal associations between the predictors and the decision to purchase, they provide useful information on two key issues. The first is whether the sales on credit led to selection into ownership of households with relatively high expected benefits from ITNs. The second is whether purchase decisions are consistent with the presence of credit and/or liquidity constraints, which would help rationalize the high uptake of ITNs sold on credit. To analyze these points, we estimate a linear probability model where the binary dependent variable is equal to one if the household purchased at least one ITN (marginal effects calculated from a probit model, not reported, are almost identical).

Variables that describe the demographic structure of the household (including presence of U5s) are not significant, either individually or jointly $(p$-value $=0.6276)$. However, we find strong associations between demand and proxy measures of perceived benefits from ITNs. First, conditional on other covariates, households where

\footnotetext{
${ }^{13}$ In addition, such concordance is not simply due to all members being reported as either having or not having used nets the night before. The correlation between the two separate reports is still very high (0.87) if we use only information from households where there is intra-family variation in reported usage.
} 
TABle 3-Correlates of ITN Purchase

\begin{tabular}{lrc}
\hline \hline & At least one ITN purchased \\
\hline $\log ($ monthly total expenditure per head) & -0.116 & $(0.053)^{* *}$ \\
Debt towards BISWA (per head, quartic root) & -0.005 & $(0.009)$ \\
Cost of malaria episodes last 6 months (per capita, quartic root $)^{1}$ & 0.019 & $(0.011)^{*}$ \\
Percentage of members who slept under net last night & 0.209 & $(0.093)^{* *}$ \\
Percentage of members who slept under ITN last night & -0.053 & $(0.279)$ \\
Nets owned by household & 0.007 & $(0.026)$ \\
Nets treated last 6 months & -0.033 & $(0.036)$ \\
Percentage of members using nets during peak season & -0.035 & $(0.079)$ \\
Any malaria-related deaths last 5 years & 0.101 & $(0.141)$ \\
Expected cost of a malaria episode (quartic root) $)^{2}$ & 0.014 & $(0.019)$ \\
Percentage of members tested positive for malaria & 0.202 & $(0.080)^{* *}$ \\
Percentage of members with self-reported malaria episodes last 6 months & 0.272 & $(0.116)^{* *}$ \\
Subjective $P\left(\right.$ malaria | untreated net) $-P(\text { malaria } \mid \text { ITN })^{3}$ & -0.066 & $(0.106)$ \\
Subjective $P\left(\right.$ malaria $\mid$ no net) $-P(\text { malaria } \mid \text { ITN })^{3}$ & -0.140 & $(0.142)$ \\
Observations & 513 & \\
$R^{2}$ & 0.11 & \\
\hline
\end{tabular}

Notes: OLS estimates of a linear probability model with a binary dependent variable $=1$ if the household purchased at least one ITN in fall 2007. Standard errors in parentheses are robust to intra-village correlation. The regressors were measured at baseline (spring 2007). Only panel households from MF villages are included. Sample size is smaller than the 589 panel households in MF villages because 76 observations ( 13 percent) have at least one regressor missing. Also included in the model are the following regressors, none of which is significant at standard levels: intercept, age, gender and schooling of household head, household size, number of members younger than 5 years old, or 5 to 14, or older than 60, measures of risk aversion and intertemporal preferences. To reduce the influence of outliers among regressors measured in rupees, values are transformed into logarithms or, when zeros are present, using the quartic root, which has a shape similar to the logarithm for positive numbers (Thomas et al. 2006). Risk aversion is measured by an indicator equal to one when the respondent chose a no-risk lottery from a list of different lotteries (played with real monetary payoff), differing in the expected value and variance of the reward. We evaluated time preferences with 12 questions where the respondent had to choose between an earlier reward and a later but larger one. The regression includes a dummy equal to one when the respondent always chose the earlier reward, and a variable recording the number of "preference reversals" implicit in the choices, which arise when an individual chose a reward at date $t$ over a larger one at date $t+s$ but preferred the later reward when the two dates were shifted by an equal time period.

*** Significant at the 1 percent level.

** Significant at the 5 percent level.

* Significant at the 10 percent level.

${ }^{1}$ Includes all actual expenses for inpatient and outpatient care, drugs, transportation, and lost household earnings.

${ }^{2}$ Expected total cost of a malaria episode for a working adult male, including all items listed above.

${ }^{3}$ The probabilities were elicited by asking respondents to express the likelihood of an event by choosing an integer between zero (impossible event) and ten (certainty).

everyone used a net prior to the intervention were $21 \mathrm{pp}$ more likely to purchase nets relative to others where no one did. This is consistent with bednets being an experience good, with past usage perhaps associated with higher perceived benefits (Dupas 2014). Second, an increase from zero to the median monetary cost of malaria episodes in the six months before the interview increased demand by $9 \mathrm{pp}\left(0.019 \times 590^{1 / 4}\right)$. Third, a history of any malaria-related deaths in the previous five years increase the predicted probability of purchase by $10 \mathrm{pp}$. However, deaths were rare (only nine respondents reported any) and the coefficient is not significant. Fourth, both self-reported malaria episodes and prevalence as measured by our blood tests are among the strongest predictors of purchase. Moving from a household with no self-reported malaria incidence to one where every member had been sick increases the probability of purchase by $27 \mathrm{pp}$. Similarly, an increase from 0 to 100 percent in the fraction of blood tests administered to the household that were positive for malaria predicts a $20 \mathrm{pp}$ increase, and both coefficients are significant 
at the 5 percent level. In contrast, we find that anemia levels are not correlated with demand for ITNs, as in Cohen and Dupas (2010). This is consistent with anemia being a poor indicator of perceived marginal benefit from ITNs, perhaps because among poor households low $\mathrm{Hb}$ levels are often caused by a number of epidemiological and nutritional factors besides exposure to malaria (de Benoist et al. 2008).

\section{B. The Role of Liquidity Constraints in Demand for ITNs}

The strong association between willingness to pay for ITNs and malaria risk overall indicates that, despite the possibility of delayed payment, non-negligible ITN prices led to significant selection. This finding suggests that credit and/or liquidity constraints (that is, lack of ability to pay) were key factors in explaining the low ITN ownership rates observed at baseline. Several pieces of evidence support this hypothesis. First, only ten of the 309 buyers in the sample chose the available option to purchase for cash. Second, households with lower monthly expenditures were more likely to purchase ITNs, despite controlling for ownership and usage of preexisting nets: a 10 percent increase in per capita expenditure predicts a 1.2 percent decrease in the probability of purchase, with the slope significant at the 5 percent level. Poorer households may have found the opportunity to purchase ITNs on credit more appealing. Third, we have shown that bednets were already present in the area, although few bednets were treated and our ITNs were overall of better quality relative to those available in local markets. Hence, high purchase rates were unlikely to be merely the result of ITNs being a new product, not available outside of the intervention.

In principle, an alternative explanation for the purchases on credit was the presence of alternative investment opportunities for their cash that yielded a return higher than the BISWA interest rate (20 percent annually). However, in that case (and in the absence of investment ceilings) one would have expected households to be maximizing their BISWA borrowing. Although we cannot rule out this possibility completely, we find that only about 14 percent of households had a current BISWA loan at follow up (excluding the ITN loan). Another possibility is that the preference for purchase on credit relative to cash was due not to liquidity constraints but to buyers having present-biased preferences. A purchase on credit could have been seen as a way to start enjoying the benefits of ITNs while postponing the associated costs. However, we find that an indicator of present-biased preferences predict neither the decision to purchase nor the choice of cash versus credit. ${ }^{14}$

To further probe the hypothesis that the relaxing of liquidity constraints was a crucial factor leading to high demand, we conducted a follow-up study between February and April 2012, where bednets were offered only for cash to BISWA households. The presence of significantly lower levels of demand in this context would support our hypothesis. Although the different timing means that we cannot rule out the possible role of time-specific factors on demand, we argue that a number of key factors were likely to a priori bias the results against the hypothesis.

\footnotetext{
${ }^{14}$ The results are available upon request from the authors. The indicator is a measure of whether the respondent exhibited "preference reversals" in a set of intertemporal choices, similarly to Ashraf, Karlan, and Yin (2006). See the Table 3 notes for additional details.
} 
Design of a Follow-up Study of Cash Sales.-We carried out the new intervention in 40 BISWA villages (Cash villages hereafter). Of these, 25 were selected at random from the 47 previous Control villages, where no ITN sales had been conducted, while the additional 15 were newly sampled from our original sampling frame. The 25 previous Control villages (PC) were included because new villages (New) were exposed to neither a comparably intense malaria and ITN-focused questionnaire nor to blood tests. If these factors were important in increasing demand in MF villages, the inclusion of only New villages might have biased results in favor of our hypothesis about the centrality of liquidity constraints. Again in order to avoid biasing the results toward finding low demand, the 40 sample villages were selected randomly after excluding communities where BISWA was no longer operational and/or where public health programs or NGOs had initiated bednet disbursal programs after the post-intervention survey in 2009. Due to funding constraints, a household-level survey was not completed for this follow-up study. However, data from the 2001 Census of India show that community-level characteristics in the 40 Cash villages were overall very similar to those of the other villages originally included in the study, and that they were also similar between PC and New villages, see online Appendix Table A.9 for details.

In cooperation with the micro-lender, field workers identified all members of BISWA self-help groups in the 40 Cash villages. An information campaign similar to that in 2007 was then conducted, discussing malaria and bednets, and describing the sale that would take place in the following days. Each BISWA household was then provided a voucher, that is, a slip of paper with the household's name and the price of the ITN printed on it. The vouchers were distributed to facilitate the calculation of the fraction of BISWA households purchasing nets (the total number of vouchers distributed being the denominator). Then, as in MF communities, sales were completed during two separate visits to the village scheduled in the following days. During each visit, BISWA members who wanted to purchase bednets did so by paying cash, on the spot, after returning the voucher. ${ }^{15}$

A key difficulty in generating comparability between the Cash and MF arm was that the nets sold in 2007 required periodic re-treatment with insecticide to maintain efficacy. As funding and timing issues did not allow us to schedule the revisits six and 12 months after the sale, we substituted the nets with Olyset ${ }^{T M}$ long-lasting insecticidal bednets (LLINs). In these nets, the insecticide permethrin is incorporated into the fabric itself, so periodic re-treatment is not necessary. The use of these LLINs has been recommended for prevention of malaria by the WHO since 2001 (World Health Organization 2001). Olyset nets have been shown to maintain their insecticidal properties even after four years in field conditions, thus guaranteeing significantly longer protection relative to the program nets delivered at the time of initial distribution. An additional advantage is that the mesh of these LLINs is wider than in most traditional bednets, so their usage in hot weather causes less discomfort because of better air circulation. Both the increased life span and the wider mesh indicate that the LLINs were a higher quality product than the ITNs sold in the 2007 intervention.

\footnotetext{
${ }^{15}$ If the voucher had been lost, a new one was created on the spot and the purchase recorded.
} 
Although these LLINs were significantly more expensive than the ITNs marketed in 2007, we priced them at a subsidized level to enhance comparability with the earlier prices in the MF intervention. Potential buyers were informed about the market price of the LLINs (it was also printed on the LLIN packaging) which was about twice as high as our offer prices. The LLINs were then either sold at the same nominal price as the ITNs sold in 2007, or at the same real price, calculated by inflating the nominal price in 2007 using a price index for rural Orissa. Randomization of prices was done at the village level so that all households in a given village were offered the LLINs at the same price. Census data show that village characteristics were overall balanced in high and low price communities, see column 3 in online Appendix Table A.9.

On the one hand, the Cash arm involved the sale of better bednets at a real price either below or identical to that relevant in 2007, with even the largest price being heavily subsidized (and advertised as such). These factors would have likely increased demand relative to what we would have observed had we implemented this Cash arm at the same time as the sales on credit, biasing a comparison with sales on credit against our hypothesis. On the other hand, the different timing of the cash sales relative to the original sale on credit implies that we cannot control for confounding time-variant factors such as changes in malaria risk.

Demand for Bednets with Cash Sales.-Vouchers were distributed to a total of 1,728 households, and 187 of these (10.8 percent) purchased a total of 275 LLINs (0.159 per household on average, or 1.5 among buying households), see Table 4 for details. As a reminder, when ITNs were offered on credit, we found that 52 percent of BISWA households purchased at least one. The difference is significant at the 1 percent level. ${ }^{16}$

Demand was very similar between PC and New villages, and we cannot reject the null that the fraction of buyers was the same between the two $(p$-value $=0.72)$. We also find that while 15 percent of households redeemed vouchers in villages where the LLINs were sold at the lower price, demand was 50 percent lower when the price was increased by 20 percent relative to 2007 to take inflation into account, a difference that is statistically significant at the 10 percent level. This implies a very high elasticity of demand equal to 2.5. This is important, because it shows that households in our study areas were very sensitive to price variations when faced with cash payments, consistent with the earlier literature that documented high elasticities of demand for health products in samples of poor African households. ${ }^{17}$

One last interesting observation emerges by looking at demand in PC villages as a function of whether the household had been included earlier in the sample (rows $\mathrm{F}$

\footnotetext{
${ }^{16}$ Taking into account that the Cash and MF samples were independent, the $t$-ratio can be calculated simply as $(0.52-0.108) / \sqrt{0.05^{2}+0.019^{2}}=7.7$.

${ }^{17}$ The difference in demand between MF and Cash interventions is even more remarkable if one takes into account the way we measured take-up. In the MF arm, this was measured as a ratio where the denominator was the number of households included in the baseline survey, conducted a few months before the IC and the sale, while the numerator was the number who purchased at least one ITN. In contrast, in the Cash arm the denominator was the number of households who received a voucher during the IC. So, a BISWA household who did not attend the IC/sale and hence did not purchase any net would have been included in the denominator and counted as not buying in MF villages, but it would have been excluded from the calculation in Cash villages, thereby biasing estimated demand for cash upwards relative to MF. If we estimate demand by replacing the number of households who received vouchers in the denominator $(1,728)$ with the number of BISWA households in the 40 villages listed in the rosters provided by the micro-lender $(1,971)$, overall demand declines from 10.8 percent to 9.5 percent.
} 
TABle 4-Results of Cash Intervention

\begin{tabular}{|c|c|c|c|c|}
\hline & & Villages & LLINs & Any LLIN \\
\hline A. & All villages & 40 & $\begin{array}{c}0.159 \\
(0.033)\end{array}$ & $\begin{array}{c}0.108 \\
(0.019)\end{array}$ \\
\hline B. & Earlier Control villages (PC) & 25 & $\begin{array}{c}0.162 \\
(0.043)\end{array}$ & $\begin{array}{c}0.103 \\
(0.022)\end{array}$ \\
\hline C. & New villages & 15 & $\begin{array}{c}0.152 \\
(0.048)\end{array}$ & $\begin{array}{c}0.119 \\
(0.037)\end{array}$ \\
\hline D. & Low price & 20 & $\begin{array}{c}0.226 \\
(0.069)\end{array}$ & $\begin{array}{c}0.149 \\
(0.039)\end{array}$ \\
\hline E. & High price & 20 & $\begin{array}{c}0.100 \\
(0.026)\end{array}$ & $\begin{array}{c}0.073 \\
(0.019)\end{array}$ \\
\hline F. & Baseline households & 25 & $\begin{array}{c}0.199 \\
(0.061)\end{array}$ & $\begin{array}{c}0.121 \\
(0.026)\end{array}$ \\
\hline G. & Non-baseline households & 25 & $\begin{array}{c}0.151 \\
(0.046)\end{array}$ & $\begin{array}{c}0.098 \\
(0.025)\end{array}$ \\
\hline & $\begin{array}{l}\text { Tests ( } p \text {-values) } \\
H_{0}: \mathrm{B}=\mathrm{C} \\
H_{0}: \mathrm{D}=\mathrm{E} \\
H_{0}: \mathrm{F}=\mathrm{G}\end{array}$ & & $\begin{array}{l}0.8779 \\
0.0944 \\
0.4638\end{array}$ & $\begin{array}{l}0.7203 \\
0.0863 \\
0.4501\end{array}$ \\
\hline
\end{tabular}

Notes: All standard errors and tests are robust to intra-village correlation of residuals. The 25 PC villages are a subset of the 47 Control villages initially included in the study, while the 15 New villages had not been selected before. "Sample households" are households in PC villages that had been earlier selected as sample households for the 2007-2009 study. The lower prices were Rs 200 for a single LLIN and 250 for a double, while the higher prices were respectively Rs 240 and 300. The price paid by our research team to Sumitomo, the manufacturer, was about twice as large.

Source: Authors' calculations from 2012 data from Cash villages.

and G). Among the 282 households who had been included in the baseline survey, 12 percent purchased LLINs. The proportion was lower but similar (9 percent) among other households who had not been part of the baseline survey. The null of equal demand between the two groups cannot be rejected at standard levels. This is potentially important, because it suggests that the earlier exposure to the survey and the RDTs had only a marginal impact on demand. In principle, exposure to the IC, to the malaria-focused questionnaire, and to the RDT results may have encouraged ITN adoption regardless of the offer of delayed repayment. In online Appendix A.6 we explore this possibility more thoroughly, making use of data from two additional data sources: first, the purchasing behavior in MF villages of BISWA households that had not been randomly selected for inclusion in the baseline survey; second, information on ITN usage and attitudes toward malaria from 25 additional villages surveyed at follow-up (in 2008-2009), where no IC or survey had been carried out earlier. Overall, we conclude that the IC was not a plausible confounder, while exposure to the survey and RDTs may have increased demand in MF villages but can only explain a small fraction of the relatively high uptake.

\section{Malaria Indicators: Descriptions and Impacts}

Next, we analyze whether the large increase in ITN ownership and usage in treatment areas was reflected in improvements in malaria indices, namely malaria prevalence and incidence and $\mathrm{Hb}$ levels. Before doing so, we clarify the nature, 
inter-relationship and measurement of the two most direct indicators of malaria burden: prevalence and incidence. This is important, both because the two indicators are not equally good measures of the direct economic burden of malaria, and because empirical findings and epidemiological models of malaria transmission suggest that they may not respond equally to public health interventions.

First, recall that in our data malaria prevalence measures the fraction of tested individuals with the disease at a given point in time, estimated from rapid diagnostic blood tests (RDTs). This is a key malaria index, also because it represents the frequency of individuals who may transmit the disease to others through Anopheles bites. ${ }^{18}$ However, in areas of intense transmission such as our study locations, individuals who test positive are frequently asymptomatic due to partial immunity acquired from repeated infections (Laishram et al. 2012). ${ }^{19}$ Accepted epidemiological models are consistent with acute episodes of malaria occurring only when a host experiences either high parasite density or in the presence of other risk factors (e.g., Ross et al. 2006). Although asymptomatic cases of malaria may not lead to significant direct costs to households, they remain of great concern for public health, because they complicate considerably attempts to eradicate or mitigate the disease.

Despite this, malaria incidence, that is, the total number of infections per person in the study population over a period of time, is often considered to be a more comprehensive measure of disease burden than prevalence. Measuring incidence accurately, however, requires repeated, regular reassessments over short periods of time and is therefore expensive and invasive. Indeed, six of the 22 ITN trials reviewed in Lengeler (2004) measured only prevalence. In our study malaria incidence was estimated from detailed recall information about illness of household members during the previous six months. ${ }^{20}$ We recorded all malaria as well as fever episodes that led to absence from work or school, or to consultation with health workers or hospitalization, noting all the related monetary costs as well as the number of days of work or school lost, see the Table 1 notes for details.

Self-reports are likely affected by recall error and misdiagnosis that may be non-random, see Strauss and Thomas (1998, Section 4). Das, Hammer, and Sánchez-Paramo (2012) found that longer recall periods led to lower reported morbidity per unit of time in a sample of individuals in Delhi, India, and that the ability to recall was correlated with socioeconomic status. In our sample, less than 1 percent of individuals were reported as having had malaria within a month of the post-intervention survey, while RDTs detected the presence of the malaria parasite in 21 percent of the tested individuals (see below). Errors of inclusion were also common, given that only 28 of the 63 individuals reported to have malaria tested positive with the RDT. In principle, errors of recall or diagnosis may have been correlated with treatment, with unclear implications for bias: for instance, the distribution of ITNs may have made the disease more salient, pushing respondents to overreport illnesses, or it may have led to a decrease in the perceived malaria risk, with opposite effects. Despite

\footnotetext{
${ }^{18}$ In addition, the completion of the life cycle of Plasmodium requires the infection of a host, so that malaria cannot spread in mosquitoes alone (White 2009).

${ }^{19}$ For instance, McMorrow, Aidoo, and Kachur (2011, Figure 1), using data from Malaria Indicator Surveys in 2007-2009, show that among children in Kenya, Mozambique, Senegal, and Zambia who tested positive, the ratio of asymptomatic to symptomatic ranged between 1.4 and 6.9.

${ }^{20}$ Pilots suggested that longer recalls led to significant respondent fatigue.
} 
these limitations, in online Appendix A.7 we show that respondent-diagnosed recent malaria episodes were strongly correlated with the results of the RDTs, and that this association was not differential across experimental arms. Overall, this suggests that self-reported incidence was thus a valuable if imperfect indicator of past malaria episodes. In addition, one advantage of respondent-diagnosed illness episodes is that they likely identify (unlike RDT-based prevalence) illnesses that were severe enough to be recognized by the household, and thus potentially more important from the viewpoint of the economic burden they imposed on the household.

In epidemiological models, prevalence and incidence are strictly linked by a relationship that depends on frequency of infection and recovery time. However, the two indicators are distinct and they may respond differently to health interventions, even when both are accurately measured with blood tests. For instance, Beier, Killeen, and Githure (1999) show that significant reductions in prevalence are usually achieved only with large reductions in the entomological inoculation rate (EIR, the number of infective bites per person/year), an indicator strictly related to incidence. ${ }^{21}$ Intuitively, an anti-malaria intervention may succeed in reducing the number of infective bites (the intensive margin) while barely affecting the probability of receiving some infective bites (the extensive margin). Indeed, substantive differences in estimated impacts of ITNs on malaria prevalence versus incidence have been found in several earlier studies. Among the 22 ITN impact studies reviewed in detail in Lengeler (2004), only seven measured both prevalence and incidence of malaria, but in all those cases the protective power of ITNs was found to be larger when looking at the latter. Two studies actually found substantial improvements in $P$ falciparum incidence while documenting higher prevalence in treated areas, although the increases were not significant at standard levels.

Empirical studies and epidemiological models of malaria transmission and ITN usage also suggest that the malaria burden is best reduced when a large fraction of the population has access to ITNs and when the nets are used regularly. Regular usage provides private benefits by limiting the number of infective bites, but a high ITN coverage rate can also be key, when it leads to substantial externalities achieved through declines in the number of mosquitoes (Binka, Indome, and Smith 1998; Hawley et al. 2003). In particular, Killeen et al. (2007) describe a rich epidemiological model calibrated using data from a number of field studies. One of their key results is that a user protected for 90 percent of the time is predicted to reduce the EIR by 60 percent relative to a nonuser if no other ITNs are used around him, but the reduction becomes close to 100 percent if everyone else in the community is also regularly using ITNs. In the previous section we have demonstrated that ITN usage increased substantially in our study areas, especially with free distribution, although usage rates remained low, with less than half of ITNs reported in use the previous night. In addition, our ITN distribution programs only targeted BISWA households, so that even in Free villages ITN coverage remained relatively low (about 20 percent on average). These factors may thus have limited the impact of our interventions, especially on malaria prevalence, and especially in MF areas,

\footnotetext{
${ }^{21}$ As few as 1-10 infective bites per person/year have been associated with prevalence rates ranging from about 10 to 80 percent, Beier, Killeen, and Githure (1999, Figure 2). In malaria-endemic areas, EIR above 100 are common. In locations close to our study districts, Sharma et al. (2006) documented EIR in the range of 3-114.
} 
where less-than-universal uptake limited ITN coverage and where we also recorded, surprisingly, usage rates lower than in Free areas, even conditional on ownership.

\section{A. Results}

We first look at the data based on RDTs, that is, malaria prevalence and Hb levels. As a reminder, at follow-up all members of sample households were targeted for testing of both malaria and $\mathrm{Hb}$, while only a subset were at baseline. At followup, 75 percent of individuals were successfully tested, while 19 percent were not because they were absent during the visits and 6 percent refused. Both refusal and absence were balanced across experimental arms (see online Appendix A.8). The ITT estimates of the program impact on RDT results are reported in Table 5, where we show results of regressions both in levels (using all tests completed at follow-up) and in DD form (for the fewer individuals tested in both surveys).

At follow-up malaria prevalence was 18.3 percent in Control areas, 22.7 percent in Free and 22 percent in MF communities (column 1). Malaria prevalence was therefore about 20 percent higher in intervention communities, although the null of no difference between each intervention arm and Control areas cannot be rejected at standard levels. ${ }^{22}$ The estimates are sufficiently precise that we can also reject the null hypothesis of large reductions in malaria prevalence in intervention relative to Control areas. The lower bound of the 95 percent confidence interval for the difference between Free and Control is -0.022 , which corresponds to a 12 percent reduction in prevalence relative to Control areas. Similarly, the corresponding lower bound for the difference between MF and Controls (-0.025) would imply a 13 percent lower prevalence than in Control villages. Several earlier RCTs evaluating the impacts of ITN adoption found reductions in prevalence substantially larger than these lower bounds (see Lengeler 2004, Appendix 8 and 9), although we have discussed above that some studies found no improvements.

The higher prevalence in Free and MF areas could have been explained in part by pre-intervention differences. The figures in Table 1 show that before the intervention malaria prevalence in Free and MF villages was respectively 7 percent and 14 percent higher relative to Control areas, although the differences were not significant at standard levels. However, the DD estimates, which only include individuals tested both before and after the intervention, are similar to the results in levels (Table 5, column 2). Relative to baseline, malaria prevalence in Control areas increased from 11 to 17.3 percent. The overall increase in prevalence was expected, because the baseline survey was completed during the hot and dry months of spring, when malaria prevalence is lower, and the follow-up survey during winter, when malaria prevalence is generally higher in Orissa (Sharma et al. 2006). Consistent with the results in levels, the increase in prevalence was 5 pp higher in Free communities and 6 pp higher in the MF arm, although again the differences are not significant at standard levels. ${ }^{23}$

\footnotetext{
${ }^{22}$ Given that ITN ownership and usage are higher in Free and MF villages relative to controls, these results also lead to a positive association between malaria prevalence and ITN usage or ownership, if one estimates the relationship with instrumental variables using treatment status as an instrument.

${ }^{23}$ When we calculate mean changes in malaria prevalence within villages, we find that prevalence declined in only 11 of 47 Control, 9 of 47 Free, and 8 of 47 MF villages, while we observe increases in prevalence in $20 \mathrm{Control}, 27$ Free, and $30 \mathrm{MF}$ communities, and no change in the remaining locations.
} 
TABLe 5-Impact of Intervention on RDT-Based Health Indices

\begin{tabular}{|c|c|c|c|c|c|c|}
\hline & \multicolumn{2}{|c|}{ +ve Malaria } & \multicolumn{2}{|c|}{ Hemoglobin } & \multicolumn{2}{|c|}{ Anemic $(\mathrm{Hb}<11 \mathrm{~g} / \mathrm{dl})$} \\
\hline & $\begin{array}{l}\text { Follow-up } \\
\text { (1) }\end{array}$ & $\begin{array}{l}\mathrm{DD} \\
(2)\end{array}$ & $\begin{array}{c}\text { Follow-up } \\
(3)\end{array}$ & $\begin{array}{r}\mathrm{DD} \\
(4)\end{array}$ & $\begin{array}{l}\text { Follow-up } \\
\quad(5)\end{array}$ & $\begin{array}{l}\mathrm{DD} \\
(6)\end{array}$ \\
\hline Free distribution $=1$ & $\begin{array}{c}0.037 \\
(0.030)\end{array}$ & $\begin{array}{c}0.054 \\
(0.040)\end{array}$ & $\begin{array}{c}-0.033 \\
(0.105)\end{array}$ & $\begin{array}{l}0.222 * * \\
(0.107)\end{array}$ & $\begin{array}{l}0.01 \\
(0.022)\end{array}$ & $\begin{array}{c}-0.024 \\
(0.033)\end{array}$ \\
\hline Micro-loans $=1$ & $\begin{array}{c}0.044 \\
(0.035)\end{array}$ & $\begin{array}{c}0.063 \\
(0.039)\end{array}$ & $\begin{array}{c}0.023 \\
(0.094)\end{array}$ & $\begin{array}{c}0.046 \\
(0.123)\end{array}$ & $\begin{array}{c}0.005 \\
(0.021)\end{array}$ & $\begin{array}{c}0.035 \\
(0.035)\end{array}$ \\
\hline Constant & $\begin{array}{l}0.183 * * * \\
(0.022)\end{array}$ & $\begin{array}{l}0.063^{* * *} \\
(0.028)\end{array}$ & $\begin{array}{l}11.433 * * * \\
(0.064)\end{array}$ & $\begin{array}{l}0.277 * * * \\
(0.075)\end{array}$ & $\begin{array}{l}0.384 * * * \\
(0.012)\end{array}$ & $\begin{array}{l}-0.111^{* * *} \\
(0.024)\end{array}$ \\
\hline $\begin{array}{l}\text { Observations } \\
\text { Clusters (villages) } \\
R^{2}\end{array}$ & $\begin{array}{c}7,154 \\
141 \\
0.0022\end{array}$ & $\begin{array}{c}1,897 \\
141 \\
0.0037\end{array}$ & $\begin{array}{c}7,149 \\
141 \\
0.0001\end{array}$ & $\begin{array}{c}1,869 \\
141 \\
0.0036\end{array}$ & $\begin{array}{c}7,149 \\
141 \\
0.0001\end{array}$ & $\begin{array}{c}1,869 \\
141 \\
0.0021\end{array}$ \\
\hline $\begin{array}{l}\text { Free }=\mathrm{MF}(p \text {-value }) \\
\text { Free }=\mathrm{MF}=0(p \text {-value })\end{array}$ & $\begin{array}{l}0.833 \\
0.3538\end{array}$ & $\begin{array}{l}0.8289 \\
0.228\end{array}$ & $\begin{array}{l}0.6058 \\
0.8749\end{array}$ & $\begin{array}{l}0.1568 \\
0.1025\end{array}$ & $\begin{array}{l}0.8474 \\
0.9043\end{array}$ & $\begin{array}{l}0.0937 * \\
0.2437\end{array}$ \\
\hline
\end{tabular}

+ve Malaria robustness checks

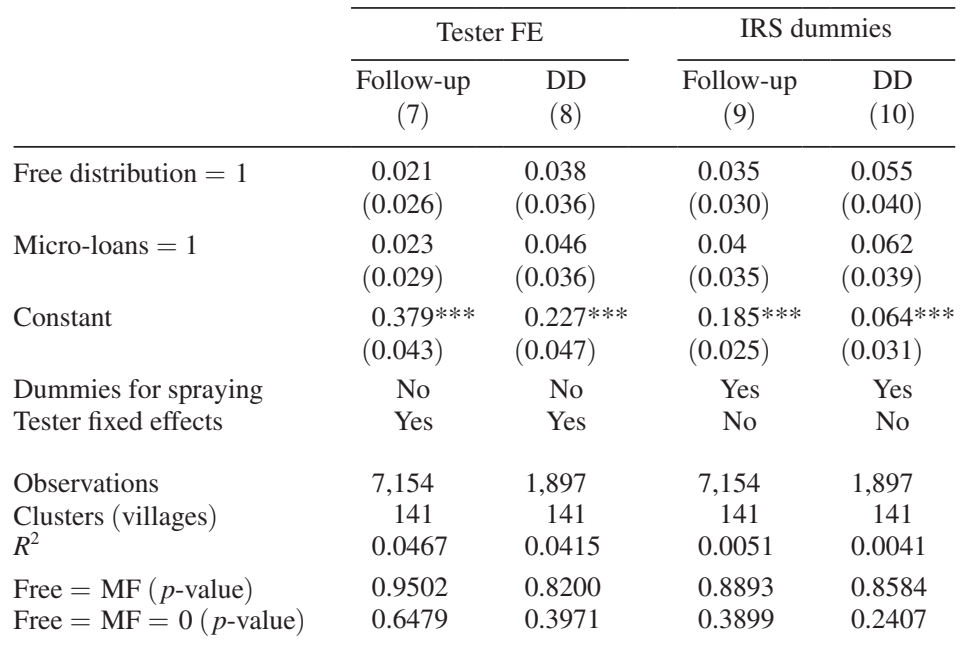

Notes: Data from baseline (spring 2007) and post-intervention household surveys (winter 2008-2009). All results are OLS estimates with individual-level observations. Standard errors (in parentheses) are robust to intra-village correlation. Estimates in columns 2, 4, 6, 8, and 10 (DD) only include tests from individuals tested both at baseline and at follow-up. In columns 7 and 8 we include fixed effects for the individuals who carried out the blood tests during the study. In columns 9 and 10 regressors also include dummies for inner walls having been sprayed in 2008-2009, a similar dummy for spraying of outer walls and two dummies $=1$ when information about spraying is missing for inner or outer walls respectively.

*** Significant at the 1 percent level.

** Significant at the 5 percent level.

* Significant at the 10 percent level.

Looking now at $\mathrm{Hb}$ levels, when we use all follow-up data, mean Hb levels was $11.4 \mathrm{~g} / \mathrm{dl}$ in Control and Free villages, and 11.5 in MF communities. The estimated impacts are therefore close to zero and not significant at standard levels (column 3). When we look at the DD estimates, we find that mean $\mathrm{Hb}$ increased by $0.28 \mathrm{~g} /$ $\mathrm{dl}$ in Control areas, 0.32 in MF and 0.50 in Free villages. ${ }^{24}$ The DD between Free

\footnotetext{
${ }^{24}$ The increases in $\mathrm{Hb}$, despite the higher malaria rate, was perhaps due to better nutrition at follow-up, conducted in months when our data indicate that income was seasonally higher for many households.
} 
and Control areas is then $0.22 \mathrm{~g} / \mathrm{dl}$, or about 14 percent of a (baseline) standard deviation and is significant at the 5 percent level. The magnitude is small but not negligible. For perspective, among the nine ITN efficacy trials reviewed in Lengeler (2004) that measured $\mathrm{Hb}$, impacts ranged from 0.2 to $1.8 \mathrm{~g} / \mathrm{dl}$, with a mean impact of $0.67 \mathrm{~g} / \mathrm{dl}$ although D'Alessandro et al. 1995, an effectiveness study such as ours, found an impact substantively lower than in our case $(0.1 \mathrm{~g} / \mathrm{dl}) .^{25}$ Thomas et al. (2006) find that an iron-supplementation program that specifically aimed at reducing anemia rates increased $\mathrm{Hb}$ levels by $0.18 \mathrm{~g} / \mathrm{dl}$ among adult males, and $0.12 \mathrm{~g} /$ $\mathrm{dl}$ among adult females.

When we look at anemia prevalence, defined as $\mathrm{Hb}<11 \mathrm{~g} / \mathrm{dl}$, we find that it was 38.4 percent in Control areas, 39.4 percent in Free and 38.9 percent in MF villages (column 5). Anemia was thus close to identical across arms, with differences not significant at standard levels. The DD results show similar patterns (column 6). The relative improvement in mean $\mathrm{Hb}$ in Free villages is reflected in a 2.4 pp reduction in anemia relative to Control, but in this case the DD is not significant at standard levels. We also find that the lack of improvements in malaria and anemia prevalence was common to all demographic groups (see online Appendix A.9 for details).

In principle, the absence of any improvement in malaria prevalence may also have been caused by measurement error, but this is unlikely in our context. First, random misclassification of a binary dependent variable leads, by construction, to negative correlation between the error and the true value of the variable. As long as the true and the mismeasured values are positively correlated (as they likely are in our case) this leads to attenuation bias (Hausman, Abrevaya, and Scott-Morton 1998, eq. 15). As prevalence tended to be higher in treatment areas, misclassification would more likely have led to underestimation of the differences. Second, at the beginning of the study, the reliability of the RDTs was successfully checked by testing a limited number of blood samples with or without malaria infection. On the other hand, during the field work RDT results were not confirmed with microscopy and a degree of subjectivity does exist in interpreting the results of the RDTs, which are read on a test strip located on a card where a reagent is added to the blood sample. The presence of recent infection with Plasmodium is signaled by the appearance of darker lines on the white strip. Although high concurrency between test readers (including non-trained ones) has been documented in clinical trials of the RDT (see online Appendix A.2), a degree of subjectivity is hard to rule out completely, because the lines can sometimes be difficult to detect when parasitemia is low. In addition, if parasitemia was declining in treatment villages over the course of the study, the likelihood of fainter, harder-to-detect test lines may have increased in these areas, which would most plausibly have led to overestimating the reduction in prevalence.

To probe further the degree of subjectivity in our context, we carried out a small validation study in collaboration with the Malaria Research Centre (MRC) field station in Rourkela, Orissa. The results showed very high sensitivity ( $>90$ percent) and specificity (74 to 85 percent), see online Appendix A.10 for details. Further, we checked whether systematic differences in the interpretation of the malaria RDT

\footnotetext{
${ }^{25}$ Several studies report the results as "packed cell volume." This can be estimated by multiplying by three the $\mathrm{Hb}$ level expressed in grams per deciliter of blood.
} 
played a role in the results by re-estimating program impacts with the inclusion of tester fixed effects (see columns 7 and 8 of Table 5). The differences among experimental arms become slightly smaller, but they remain positive and not significant at standard levels.

Finally, measurement error was unlikely to be a problem for the $\mathrm{Hb}$ testing, which also showed mixed evidence of differential changes across experimental groups. Although erroneous testing cannot be ruled out entirely, measuring $\mathrm{Hb}$ simply requires reading a number from the display of a small diagnostic piece of equipment. In addition, the strong cross-sectional correlation between malaria infection status and $\mathrm{Hb}$ levels supports the reliability of the malaria RDTs. When we regress $\mathrm{Hb}$ on a dummy for a positive malaria test, the slope $(=-0.19)$ is significant at the 1 percent level.

We also evaluate the hypothesis that malaria indices remained high due to behavioral changes that may have compensated for the benefits of ITNs. The increased availability of ITNs in Free and MF villages may have reduced the use of alternative prophylactic measures such as indoor or outdoor wall spraying with insecticide, mosquito coils, or the control of drainage pools. We tested this hypothesis using data on knowledge and practices collected during the post-intervention survey, but the differences between arms are generally small and show no systematic pattern, see online Appendix A.11 for details. A potentially important exception is wall spraying which, like ITNs, is widely considered an effective mean of reducing malaria risk (World Health Organization 2007). In Control areas, 40 percent of households had the inner walls sprayed after 2007, while the proportion was 37 percent in Free and 30 percent in MF communities. The proportions who had the outer walls sprayed in the three groups were respectively 53, 48, and 44 percent. Although the null of equality is not rejected, the magnitude of the differences is relatively large. We then reestimate the ITT including dummies for recent wall spraying among the regressors. Spraying is potentially endogenous, but here we are only interested in evaluating whether differences in spraying rates help explain the lack of health benefits in intervention villages. In columns 9 and 10 of Table 5 we show that this leaves the estimated impacts on malaria prevalence almost identical (the results for $\mathrm{Hb}$ are similar too and are available upon request). Overall, then, we find no evidence that our results are due to changes in household risk-coping behavior.

Similarly, the lack of effect on malaria or anemia prevalence cannot be explained by the presence of other ITN distribution programs, possibly sponsored by the Government or by other NGOs. First, the results on net ownership in Table 2, which showed large increases in ITN ownership rates in treatment versus Control areas, included nets from all sources. Second, we find that the number of nets received from non-BISWA sources was very small and not significantly different across all arms, see Table A.12 in the online Appendix for details.

An additional concern is the possibility that malaria and anemia prevalence did not improve either because the bednets had not been treated appropriately with deltamethrin (the insecticide), or because the local population of Anopheles mosquitoes was or became resistant to the chemical. We cannot address these concerns directly, because our data include neither systematic measurements of the insecticide concentration on the ITNs nor information on number, behavior, and susceptibility to insecticide of local Anopheles. We argue, however, that these 
factors were unlikely to be central. First, all bednet treatments were conducted by our trained personnel, using appropriate procedures and chemical concentrations, and tests run on a small number of ITNs at the end of the study were consistent with adequate treatment, see online Appendix A.4 for details. Second, none of a number of recent studies carried out in Orissa and Madhya Pradesh (another Indian state) point to ITNs as a plausible cause of resistance to deltamethrin, see online Appendix A.12. In addition, resistance to insecticides is unlikely to develop over a relatively short period of time in a situation such as ours, where ITN use was largely limited to a study population (BISWA members) that always represented a minority of the village.

Next, we analyze our data on respondent-reported malaria incidence. Although recall error make these data less reliable than RDTs, we have argued above that (abstracting from such concerns) incidence is perhaps the best measure of disease burden. In Table 6 we show the estimated ITT program impacts on a number of selfreported malaria indicators. We only discuss the DD estimates because, unlike the RDTs, some of the self-reported outcomes were not balanced at baseline, suggesting higher malaria burden in Free and MF areas relative to Control, see Table 1. We first look at the fraction of individuals with episodes of malaria that are still ongoing or recent (within a month). These figures can be interpreted as self-reported prevalence and (as we noted before) are remarkably low, likely suggesting that most malaria cases identified by RDTs were asymptomatic.

In Control areas only 0.7 percent of individuals were reported as having had malaria during the last month and, consistent with the RDT-based prevalence results, the null of equality across arms cannot be rejected. In contrast, measures of incidence over the previous six months show beneficial impacts of ITNs, both in Free and in MF villages. In Control areas, mean incidence at follow-up was 0.115 episodes per person over six months, an increase of 0.025 relative to baseline likely due to the seasonal pattern of the disease. However, the DD for both Free and MF indicate a relative decline in incidence of about the same magnitude, and the coefficient is significant at the 5 percent level in Free villages, and at the 1 percent level in MF. The magnitude of these impacts is large relative to Control conditions, with a relative risk ratio of $0.56=(0.115-0.051) / 0.115$, broadly consistent with the reduction in uncomplicated clinical episodes observed in earlier efficacy studies, see Lengeler (2004, Appendix 6 and 7). In addition, and given that the average household had about 5.5 members, these estimates indicate a relative decline of $2 \times 0.05 \times 5.5=0.55$ episodes of malaria per household per year.

An important caveat is that a fraction of these malaria cases were in fact likely misdiagnosed fever episodes. Recall that we find that RDT results and respondentdiagnosed recent malaria cases only coincided in 44 percent of cases, with similar rates of concurrence among experimental arms (see also online Appendix A.7). The actual impact on symptomatic malaria incidence was thus likely smaller than suggested by the results in column 2 of Table 6. In online Appendix A.13 we show that the estimates are about 40 percent smaller (but still significant at standard levels) if we assume that only 44 percent of incidence was correctly diagnosed, while also considering that a fraction of respondent-reported fever cases were likely misdiagnosed cases of symptomatic malaria. Regardless of this adjustment, the estimates are substantively large, given that at baseline the average monetary cost of a malaria 
Table 6-Impact of Intervention on Self-Reported Malaria Indices

\begin{tabular}{|c|c|c|c|c|c|c|c|}
\hline & \multirow{3}{*}{$\begin{array}{l}\text { Malaria } \\
\text { previous } \\
\text { month } \\
(1)\end{array}$} & \multicolumn{6}{|c|}{ Malaria and episodes in 6 months before interview } \\
\hline & & \multirow[b]{2}{*}{$\begin{array}{l}\text { Number of } \\
\text { episodes } \\
\text { (2) }\end{array}$} & \multirow[b]{2}{*}{$\begin{array}{l}\text { Days of work } \\
\text { or school lost } \\
\text { (3) }\end{array}$} & \multicolumn{2}{|c|}{ Health expenditures } & \multirow{2}{*}{$\begin{array}{c}\text { Episodes } \\
\text { paid for } \\
\text { with debt } \\
(6)\end{array}$} & \multirow{2}{*}{$\begin{array}{c}\text { Episodes paid } \\
\text { for with lower } \\
\text { consumption } \\
\text { (7) }\end{array}$} \\
\hline & & & & $\begin{array}{l}\text { All } \\
(4)\end{array}$ & $\begin{array}{c}\text { Doctors } \\
\text { and drugs } \\
(5)\end{array}$ & & \\
\hline Free distribution $=1$ & $\begin{array}{c}-0.004 \\
{[0.004]}\end{array}$ & $\begin{array}{l}-0.048 \\
{[0.018]^{* *}}\end{array}$ & $\begin{array}{c}-1.9 \\
{[1.2]}\end{array}$ & $\begin{array}{l}-194 \\
{[180.1]}\end{array}$ & $\begin{array}{l}-86 \\
{[100.1]}\end{array}$ & $\begin{array}{l}-0.11 \\
{[0.05]^{* *}}\end{array}$ & $\begin{array}{l}-0.12 \\
{[0.06]^{* *}}\end{array}$ \\
\hline Micro-loans = 1 & $\begin{array}{c}-0.002 \\
{[0.004]}\end{array}$ & $\begin{array}{l}-0.051 \\
{[0.018]^{* * *}}\end{array}$ & $\begin{array}{l}-2.4 \\
{[1.1]^{* *}}\end{array}$ & $\begin{array}{c}-269.3 \\
{[143.4]^{*}}\end{array}$ & $\begin{array}{l}-187.2 \\
{[76.5]^{* *}}\end{array}$ & $\begin{array}{l}-0.11 \\
{[0.05]^{* *}}\end{array}$ & $\begin{array}{l}-0.09 \\
{[0.05]^{*}}\end{array}$ \\
\hline Constant (Control) & $\begin{array}{c}-0.001 \\
{[0.003]}\end{array}$ & $\begin{array}{c}0.025 \\
{[0.013]^{*}}\end{array}$ & $\begin{array}{c}1.5 \\
{[0.8]^{*}}\end{array}$ & $\begin{array}{l}238.2 \\
{[110.2]^{* *}}\end{array}$ & $\begin{array}{l}168.8 \\
{[54.6]^{* * *}}\end{array}$ & $\begin{array}{l}0.07 \\
{[0.04]^{*}}\end{array}$ & $\begin{array}{l}-0.18 \\
{[0.03]^{* * *}}\end{array}$ \\
\hline Endline level (Control) & 0.007 & 0.115 & 5.8 & 862.8 & 486.8 & 0.22 & 0.07 \\
\hline Unit of observation & Individual & Individual & Household & Household & Household & Household & Household \\
\hline Observations & 8,684 & 8,684 & 1,768 & 1,768 & 1,768 & 1,768 & 1,768 \\
\hline Free $=\mathrm{MF}=0(p$-value $)$ & 0.6065 & $0.0087 * * *$ & $0.0862 *$ & 0.1713 & $0.053 *$ & $0.0326 * *$ & $0.077 *$ \\
\hline Free $=\operatorname{MF}(p$-value $)$ & 0.5873 & 0.8557 & 0.7043 & 0.6578 & 0.3105 & 0.942 & 0.6285 \\
\hline
\end{tabular}

Notes: Data from baseline (spring 2007) and post-intervention household surveys (winter 2008-2009). All results are OLS estimates of difference-in-differences models. All outcomes refer to malaria episodes diagnosed as such by the respondent. Monetary values are in 2008-2009 Rupees and are at the household level. In column 4, "all" health expenditures were elicited using an itemized list that included doctor fees, drugs, and tests, hospitalization, surgery, costs of lodging and transportation (including those for any caretaker), lost earnings from days of lost work, and cost of non-household members hired to replace the sick at work. Standard errors (in brackets) and tests are robust to intra-village correlation.

*** Significant at the 1 percent level.

** Significant at the 5 percent level.

* Significant at the 10 percent level.

episode was close to Rs 1,000 , about 30 percent of total monthly household expenditure. The estimates are also large relative to the price of our program ITNs, which cost at most Rs 259. Note also that the estimates are ITT, surely a lower bound of the average benefit for the treated.

The changes in incidence were also reflected in the costs borne by households due to self-reported malaria cases (columns 3-7). In both arms, the DD show an average reduction per household of about two days of school or work lost due to malaria, relative to an endline average of 5.8 days in Control areas. In Control areas, we estimate that malaria cost Rs 863 per household during the previous six months, about 3 percent of total household expenditure during the same period. Relative to Control areas, free distribution of ITNs was associated with a Rs 194 lower expenditure due to malaria, while the reduction was Rs 269 in MF villages, although only the latter is significant, at the 10 percent level. Such reductions correspond respectively to 23 percent and 31 percent of estimates of total malaria costs over a six month period in Control areas at endline. ${ }^{26}$ The figures in column 5 show that a large part of these costs were due to doctors and drugs. Finally, we find that the

\footnotetext{
${ }^{26}$ The estimates in columns 3-7 (as those in column 2) do not distinguish between correctly self-diagnosed malaria cases and other sickness episodes incorrectly diagnosed as malaria. We are interested in impacts on costs regardless of whether they were actually due to malaria because respondents sought treatment based on their perceptions (hence perceptions are what matters) and the ITNs may plausibly have led to improvements in overall health as well due to decreased malaria burden. Note also that the impacts on malaria and fever pooled together are qualitatively similar to those for malaria only but the magnitudes are larger (see online Appendix Table A.14 for details).
} 
interventions were associated with a relative decline of about 0.1 in the number of malaria episodes that forced the households to incur debt or reduce consumption to cope with the necessary costs. These DD are significant at the 10 percent or below and are large relative to the levels in Control villages.

\section{B. Interpretation and Discussion}

Overall, self-reported malaria incidence rates are thus in stark contrast with prevalence as measured with RDTs, both in terms of levels and in terms of changes over time. Reporting error on malaria incidence correlated with the intervention could explain at least in part these findings, but as we described earlier substantive differences in impacts on prevalence versus incidence are not unique to our study. Our findings are thus consistent with the hypothesis that the increase in ITN usage reduced infective bites enough to reduce the case-incidence of acute malarial episodes, but not enough to reduce the overall prevalence of malaria.

Low usage and coverage rates may have contributed to these findings. First, despite the substantive increases in ITN usage documented in Table 2, only 45 percent of the program ITNs were in use the night before the follow-up survey in Free areas, and about one-third fewer were in use in MF villages. Second, it must be recalled that only BISWA clients received free ITNs or the offer of ITNs for sale on credit. Although BISWA had a large presence in the study area, we estimate that on average only 20 percent of people lived in households with at least one BISWA affiliate and thus were eligible for inclusion in the study. Even in villages where nets were distributed for free, ITN coverage was therefore low, nowhere larger than 50 percent and with only four villages where it surpassed 30 percent. With a 20 percent coverage and a frequency of usage equal to the 45 percent cross-sectional usage rate, the epidemiological model of Killeen et al. (2007) (leaving all other calibrated parameters unchanged) predicts a reduction in infective bites of about 40 percent for users and significantly less for non-users, see online Appendix A.14 for details. Such declines, while substantive, may have been too small to be detected by measures of prevalence (Beier, Killeen, and Githure 1999). Of course these calibrations have to be taken with caution because the model in Killeen et al. (2007) depends on a number of parameters - such as species, number, and feeding habit of Anophelesthat we do not observe in our data.

Our data are not ideal to study the role of community-level ITN coverage on malaria prevalence, both because the fraction of the population treated in intervention villages (BISWA households) was always small and because random assignment of treatment was not stratified by BISWA degree of presence in the village. Perhaps for these reasons, we find no clear association between changes in prevalence and estimates of ITN coverage achieved via free distribution, see online Appendix A.15 for details. We also investigate the extent of within-village externalities, by using geo-coded data from a subsample of 11 villages, 4 Control, and 7 Free. We estimate a model where malaria status is regressed on the number of total and BISWA neighbors within different radii, both interacted with the Free dummy. The point estimates suggest substantial externalities at short ranges, with lower prevalence in Free villages associated with increases in the number of BISWA neighbors within 5-20 meters (a proxy for local ITN coverage). This is consistent 
with the existence of clusters of ITN-related protection, and with the argument that higher coverage rates may have led to declines in prevalence. However, the small sample leads to very imprecise estimates that are not significant, see online Appendix A.16 for details.

To help rationalize the lack of improvement in malaria prevalence, it is also useful to compare our study design with that of the 22 ITN efficacy studies reviewed in Lengeler (2004). Fourteen were, like ours, clustered randomized trials, while in the remaining eight ITNs were randomly assigned within community. Among the clustered RCTs, the largest impacts of ITNs were found where community-level coverage was very high. In all trials, the number of ITNs distributed was sufficient to ensure that a majority of sleeping spaces were protected by nets in treatment communities. In addition, six of the seven clustered RCTs that measured impacts on malaria prevalence achieved close to universal coverage. The one exception is D'Alessandro et al. (1995), which is also the only "effectiveness" study surveyed in Lengeler (2004). That is, while all other studies evaluated benefits of ITNs under ideal trial conditions ("efficacy"), this study focused on sentinel sites for the evaluation of a public health program in The Gambia. After one year, they observe substantial improvements in malaria indices among children in treated areas. However, they also show that prevalence was actually higher (71 versus 45 percent) in treatment relative to Control areas in one of the five sentinel sites, despite no evidence of resistance to insecticide. As a likely key explanation they mention "low usage of nets by children in this area" (D'Alessandro et al. 1995, p. 482). More evidence about the importance of high coverage is also found in Kroeger, González, and Ordóñez González (1999), a study carried out in Nicaragua where the fraction of individuals reported as sleeping under ITNs ranged between 5 and 70 percent. They find that declines in incidence were smaller in areas with lower coverage, with no improvements detected when coverage was $<16$ percent.

The studies with intra-community assignment of ITNs (and hence low community-wide coverage rates) found 40-60 percent declines in malaria incidence. However, as in our case, prevalence increased in treated areas in two of the studies. Moreover, in these studies usage rates were reported to be very high ( 70 percent or above), while in our context less than half of the ITNs were reported as being used the previous night. ${ }^{27}$ It is possible that such high usage rates were achieved because these studies (unlike ours) involved intense monitoring of net usage and/or health outcomes, including a combination of nightly surprise visits and frequent (sometimes daily) health checks. Such a study design could have induced behavioral responses such as increased compliance with regular ITN usage.

In sum, taking both the biomarkers and the self-reports as broadly correct, we conclude that our intervention reduced the incidence of severe malaria cases sufficiently to lead to declines in malaria-related expenditures that were large relative to Control conditions. On the other hand, we also found no improvements in prevalence, and comparisons with the existing literature on ITN efficacy and malaria epidemiology suggest that this was likely the result of relatively low usage rates and population coverage.

\footnotetext{
${ }^{27}$ Unlike our project, all of these eight studies were also carried out within relatively small geographical areas, with the exception of one where the study population was spread across one district.
} 


\section{Cost Effectiveness Analysis}

The cost-effectiveness comparison between free distribution and sales on credit would be trivially in favor of micro-loans if repayments were complete and take-up comparable between arms, but neither condition held in reality. Together with the cost of the ITN themselves (which included delivery at the BISWA headquarters in Sambalpur), distribution expenses included costs for labor and for transporting the ITNs from Sambalpur to the villages. Based on field expenses, we estimate a transport cost of Rs 500 per day and wages of Rs 150 per day per worker, and about 1.5 days to cover a village. If our intervention were scaled up through a microfinance network, these delivery costs could be lower if the delivery operations were scheduled using the MFI's existing labor and transportation resources. Insecticide treatment costs were Rs 10-13 per net (depending upon size). Dividing the total cost thus obtained by the number of ITNs distributed in each arm lead to a cost per ITN delivered of Rs 305 in MF villages and Rs 225 with free provision.

Turning to revenues, recall that the price charged to buyers already covered BISWA's costs in administering the loan. However, at the time of the follow-up survey, about 1.5 years after the sale, sample households in MF communities had repaid on average 64 percent of ITNs, and we assume that no further payments were made afterwards. The low repayment rates were largely due to some BISWA program officers not putting effort into enforcing repayments, especially in certain districts. This was despite what was conveyed to BISWA members at the time of the sales, when they were informed that loan defaults would have been treated as for any other BISWA loan. Note that our data are not consistent with households anticipating that repayment would be scarcely enforced in some areas. This is important, because if households had anticipated such enforcement behavior, the high demand for ITNs on loan could have been a mere by-product of "sales" actually perceived as free or highly subsidized distribution. However, we find a positive correlation between demand for ITNs and share of the loan repaid across study districts.

Overall, there are thus two key drivers of the differences in cost per ITN in the two arms. On the one hand, about four times as many ITNs were delivered in Free villages, thus lowering considerably the incidence of fixed costs per ITN distributed. On the other hand, in MF villages a substantial fraction of costs were recouped through repayments. These calculations yield a cost per ITN of about Rs 150 in MF villages and Rs 225 in Free villages. Sales on credit, despite repayment and fixed cost concerns, were thus considerably more cost-effective in the sense that for a fixed budget, 50 percent $(=100 \times[(1 / 150)-(1 / 225)] /(1 / 225))$ more nets can be distributed relative to free disbursal. However, given that purchase rates were well below 100 percent, covering the same number of households under MF would require ITNs to be distributed across more villages. For instance, the 4,000 nets that we distributed in total in the 47 Free communities would have required reaching about 200 villages if they had to be sold on credit. An important corollary is that cost effectiveness was achieved at the expense of significantly lower within-village ownership rates relative to free distribution. To the extent that externalities from mass distribution are an important source of ITN protective efficacy, cost-recovery may be suboptimal since it will likely result in lower ITN densities. 
An alternative way to evaluate the two delivery schemes is to consider their relative cost of reaching "high benefit" households, defined crudely as those where any of the members had malaria at baseline. By this metric, 60 percent of all households were high benefit. In MF villages, such households were $17 \mathrm{pp}$ more likely to purchase an ITN. These considerations would tilt cost-effectiveness further in favor of micro-loans, implying that the cost of reaching a high benefit household using micro-loans was Rs 227 and the corresponding figure with free distribution was Rs 375 , that is, two-thirds higher.

\section{Discussion, Limitations, and Conclusions}

Liquidity constraints have been hypothesized to be a key reason behind the low adoption rates of beneficial preventative health products among the poor in developing countries. In this paper, we implement a randomized controlled trial to argue that micro-consumer loans may provide a feasible and cost-effective method to increase adoption in situations where existing markets and public health interventions have not been successful at ensuring adequate coverage of ITNs, which are one of the most efficacious malaria prevention methods. In a treatment arm composed of 47 villages in rural Orissa (India), our program succeeded in selling about 1,100 ITNs on credit to clients of a micro-lender over a few months, despite the relatively high price of the ITNs, about 3-5 times the daily agricultural wage in the study area. This increased ITN ownership substantially relative to Control areas, with 52 percent of sample households purchasing at least one net.

These purchase rates are substantially higher than in earlier studies that found very low cash purchases of health products among the poor, despite heavy subsidization (Ashraf, Berry, and Shapiro 2010; Cohen and Dupas 2010; Kremer and Miguel 2007; and Kremer et al. 2009). Consistent with these studies, we also find that the demand for bednets in our study areas was significantly lower (11 percent) and highly price-elastic when households had to pay up front in cash. However, cash sales were conducted at a later time with respect to the sales on credit, so we cannot exclude the presence of time-varying confounders. On the other hand, we have described a number of factors that were likely to bias demand for ITNs offered for cash upwards relative to what we observed in the sales on credit. We also provide additional evidence that liquidity constraints played a key role in explaining the high adoption rates of ITNs sold on credit, including the fact that only a handful of buyers chose to pay cash, despite the option being available at the time of the sales on credit.

We also found clear evidence of selection into purchase, with indicators of past exposure to malaria strongly associated with demand. In contrast, in a sample of women in rural Kenya, Cohen and Dupas (2010) found no correlation between low levels of $\mathrm{Hb}$ levels and willingness to pay for ITNs. This is possibly due to $\mathrm{Hb}$ being a noisy indicator of malaria exposure, and indeed we also find no association. However, an alternative hypothesis is that demand among at-risk women was reduced by positive correlation between malaria risk and liquidity constraints, that is, by a negative correlation between willingness to pay and ability to do so. In our setting, liquidity constraints were relaxed by the loan offer, and so correlates of demand were less likely to confound willingness and ability to pay. 
Despite a two-thirds repayment rate of loan at the time of the follow-up survey, 1 to 1.5 years after the sales, we estimate that sales on credit reduced the estimated cost of reaching a household at risk (defined as one where any of the members had malaria at baseline) by about 50 percent relative to free distribution. Such considerations may be important for public health programs that aim at maximizing the number of at-risk beneficiaries within the constraints of a given budget. In situations where funding is only sufficient to offer protection to high-risk individuals — such as pregnant women and young children-micro-loans may perhaps help in approaching universal coverage by increasing adoption among individuals-such as working adults - for whom episodes of clinical malaria may still lead to substantive economic costs. However, these factors must be weighted against the lower product coverage achievable with cost-sharing relative to free distribution, even when the product is offered on credit. This is a potentially serious drawback in the presence of externalities.

When we estimate the program impacts on malaria indices, the results are mixed. First, we find no evidence of substantial improvements in malaria or anemia prevalence (the fraction of the population affected by the condition) when measured from blood samples. We find an improvement (significant at the 5 percent level) in mean $\mathrm{Hb}$ in areas with free distribution, but only when we use differences-in-differences estimates. In contrast, we find substantial and statistically significant improvements in malaria incidence (the number of cases over a period of time) in areas where nets were either donated or sold on credit, although these results are based on recall data and were not clinically validated. Incidence was thus surely measured with error, and our data suggest that a large majority of malaria cases detected with RDTs were asymptomatic, a common finding in malaria endemic areas (such as Orissa) where repeated exposure to the disease generates partial immunity. Fever cases misdiagnosed as malaria were also likely common, although we have argued that recall data remain a useful if biased proxy of symptomatic malaria cases, severe enough to be recognized within the household.

The relative reduction in malaria incidence was also associated with lower health expenditures, fewer days of work or school lost due to malaria, and fewer episodes forcing the household to incur debt or lower consumption to pay for the related costs. The ITT estimates suggest an average yearly saving in malaria-related health expenditure about twice as large as the most expensive ITNs sold through our program. Given that the average impacts on the treated was likely higher, and that our high quality ITNs should have lasted at least 2-3 years, these figures suggest that liquidity constraints imposed substantial health-associated costs on the households. In addition, these figures ignore the welfare gains that arose directly from enjoying better health.

To reconcile the absence of improvements in prevalence and the substantial decline in self-diagnosed incidence, we go back to the numerous earlier field trials of ITN efficacy and to accepted epidemiological models of malaria transmission. Consistent with our results, we find that studies that reported both malaria prevalence and incidence systematically found larger improvements using the latter measures, and some studies (like ours) actually found increases in prevalence after the introduction of ITNs in treatment areas. Substantive declines in prevalence have been argued to be unlikely to emerge without large declines in the number of infective 
mosquito bites. In turn, such declines are only likely to arise when ITN coverage is high and/or ITN usage is very regular. By design, our study only targeted BISWAaffiliated households, with the consequence that even with free distribution ITN coverage rates rarely surpassed 30 percent within the village. In addition, although a large majority of ITNs were retained by households, usage was relatively low at the time of the follow-up visits, with 45 percent of free ITNs reported as having being used the night before and (somewhat surprisingly) lower usage rates for nets purchased on credit.

Even taking the reduction in self-diagnosed incidence at face value, the lack of improvements in RDT-assessed prevalence remain a concern, because it suggests that the potential reservoir for infection remained unabated in study areas. This is important, because although asymptomatic cases may not lead to substantive health or economic costs for the individual affected, sub-clinical malaria can still be transmitted to others, so that it remains "a major hurdle for malaria elimination, as infected hosts serve as silent reservoirs" (Laishram et al. 2012, p. 9, see also Vinetz and Gilman 2002). Unfortunately, our study was not designed to measure entomologic indicators such as anopheline density, biting rates, and behaviors. We were thus not able to assess directly any program impacts on these key channels through which ITNs exert their protective effect.

We also emphasize that low coverage and irregular usage are likely to mimic more closely the result of actual public health interventions ("effectiveness") than studies carried out under ideal trial conditions ("efficacy"). From this perspective, the results of our trial should also be of relevance for the public health literature, given that almost all the results surveyed in Lengeler (2004) are "from randomized controlled trials where the intervention was deployed under highly controlled conditions, leading to high coverage and use rates. [...] While the difference between efficacy and effectiveness is likely to be small for certain medical interventions (such as vaccination or surgery), it can potentially be large for preventive interventions such as ITNs" (Lengeler 2004, p. 10). Importantly, the unique features of our study design also imply that our results should not be interpreted as contradicting such earlier studies on the efficacy of ITNs. Our findings on the health impacts of ITNs should rather be seen as complementing the existing literature and suggest that public health interventions which only achieve the distribution of a relatively limited number of ITNs and/or do not ensure regular usage may fail to achieve the desired effects. Much more may be needed, and efforts should include ensuring high village-wide coverage, providing incentives for regular use, and possibly adding complementary interventions such as indoor residual spraying, case management and environmental measures.

We conclude by emphasizing a number of additional factors that may limit the external validity of our results. First, although our study area comprised 141 villages from a very wide geographical area, the study population was not a representative sample of the five districts where we operated. Our study villages were selected because BISWA already had a presence there, and only BISWA clients were eligible for the intervention. Therefore, our study does not identify the impacts of introducing sales of ITNs on credit in a population with no access to BISWA's credit network. Extending sales to non-BISWA clients within our study communities could have increased the overall coverage of ITNs within the village, but our data are 
silent about this, and the implications on the expected repayment rates are unclear. Second, ITN adoption among sample households may have been raised beyond what was achievable by micro-loans only by the information content of the information campaign, survey, and blood tests that preceded the sales. Should a micro-loan program such as ours be scaled up, at least some of these factors would be unlikely to be replicated. On the one hand, we do find evidence that the results of the blood tests (immediately divulged to the individuals or the guardian) affected demand for ITN offered on credit, and we also observe higher demand among households included in our baseline survey relative to non-sample households. On the other hand, we have argued that exposure to the information campaign was not a plausible confounder, and that being part of the baseline survey can explain at most part of the success of the micro-loan program at increasing ITN adoption.

One additional limitation is that the bulk of the study was conducted with standard ITNs, and not with the long-lasting insecticidal nets (LLINs) that are being increasingly used in many mass distribution campaigns, particularly in Africa. We chose the inclusion of ITNs for the study because LLINs were not available in the area-and to the best of our knowledge remain so-and we favored a product that was available locally in case local NGOs wanted to implement similar interventions. We only adopted LLINs when we implemented cash sales, after the conclusion of the main study, but funding constraints did not allow us to evaluate health impacts. The choice of LLINs for free distribution or sale on credit may have provided a more reliable insecticide concentration on the ITNs in the field, given that they are factory pretreated, more wash resistant, and do not need to be re-treated every six months. In the paper we argue that the guidelines followed for the re-treatment of the standard ITNs adopted in the main study, as well as the choice of insecticide, should have guaranteed their effectiveness. Despite this, we cannot exclude the possibility that LLINs may have led to better health impacts.

\section{REFERENCES}

Agha, Sohail, Ronan Van Rossem, Guy Stallworthy, and Thankian Kusanthan. 2007. "The Impact of a Hybrid Social Marketing Intervention on Inequities in Access, Ownership and use of InsecticideTreated Nets." Malaria Journal 6 (1): 13.

Alam, Khurshid, and Shakil Ahmed. 2010. "Cost Recovery of NGO Primary Health Care Facilities: A Case Study in Bangladesh." Cost Effectiveness and Resource Allocation 8 (6): 12.

Ashraf, Nava, James Berry, and Jesse M. Shapiro. 2010. "Can Higher Prices Stimulate Product Use? Evidence from a Field Experiment in Zambia.” American Economic Review 100 (5): 2383-2413.

Ashraf, Nava, Dean Karlan, and Wesley Yin. 2006. "Tying Odysseus to the Mast: Evidence from a Commitment Savings Product in the Philippines." Quarterly Journal of Economics 121 (2): 635-72.

-Barreca, Alan I. 2010. "The Long-Term Economic Impact of In Utero and Postnatal Exposure to Malaria." Journal of Human Resources 45 (4): 865-92.

Beier, John C., Gerry F. Killeen, and John I. Githure. 1999. "Short Report: Entomologic Inoculation Rates and Plasmodium Falciparum Malaria Prevalence in Africa." American Journal of Tropical Medicine and Hygiene 61 (1): 109-13.

Binka, F. N., F. Indome, and T. Smith. 1998. "Impact of Spatial Distribution of Permethrin-Impregnated Bed Nets on Child Mortality in Rural Northern Ghana." American Journal of Tropical Medicine and Hygiene 59 (1): 80-85.

Bleakley, Hoyt. 2010. "Malaria Eradication in the Americas: A Retrospective Analysis of Childhood Exposure." American Economic Journal: Applied Economics 2 (2): 1-45.

Cohen, Jessica, and Pascaline Dupas. 2010. "Free Distribution or Cost-Sharing? Evidence from a Randomized Malaria Prevention Experiment." Quarterly Journal of Economics 125 (1): 1-45. 
Cutler, David, Winnie Fung, Michael Kremer, Monica Singhal, and Tom Vogl. 2010. "Early-Life Malaria Exposure and Adult Outcomes: Evidence from Malaria Eradication in India." American Economic Journal: Applied Economics 2 (2): 72-94.

D’Alessandro, U., B. Olaleye, P. Langerock, M. K. Aikins, M. C. Thomson, M. K. Cham, B. M. Greenwood, et al. 1995. "Mortality and Morbidity from Malaria in Gambian Children after Introduction of an Impregnated Bednet Programme.” Lancet 345 (8948): 479-83.

-Das, Jishnu, Jeffrey Hammer, and Carolina Sánchez-Paramo. 2012. "The Impact of Recall Periods on Reported Morbidity and Health Seeking Behavior." Journal of Development Economics 98 (1): 76-88.

de Benoist, Bruno, Erin McLean, Ines Egli, and Mary Cogswell. 2008. Worldwide Prevalence of Anaemia 1993-2005: WHO Global Database on Anaemia. World Health Organization Report, Geneva.

Devoto, Florencia, Esther Duflo, Pascaline Dupas, William Parienté, and Vincent Pons. 2012. "Happiness on Tap: Piped Water Adoption in Urban Morocco." American Economic Journal: Economic Policy 4 (4): 68-99.

Dupas, Pascaline. 2011. "Health Behavior in Developing Countries." Annual Review of Economics 3 (1): 425-49.

Dupas, Pascaline. 2014. "Short-Run Subsidies and Long-Run Adoption of New Health Products: Evidence from a Field Experiment." 89 (1): 197-228.

-Fink, Günther, and Felix Masiye. 2012. "Assessing the Impact of Scaling-up Bednet Coverage through Agricultural Loan Programmes: Evidence from a Cluster Randomised Controlled Trial in Katete, Zambia." Transactions of The Royal Society of Tropical Medicine and Hygiene 106 (11): 660-67.

Gallup, John Luke, and Jeffrey D. Sachs. 2001. "The Economic Burden of Malaria.” American Journal of Tropical Medicine and Hygiene 64 (1S): S85-96.

-Gersovitz, Mark, and Jeffrey S. Hammer. 2004. "The Economical Control of Infectious Diseases." Economic Journal 114 (492): 1-27.

Gersovitz, Mark, and Jeffrey S. Hammer. 2005. "Tax/Subsidy Policies toward Vector-Borne Infectious Diseases." Journal of Public Economics 89 (4): 647-74.

-Hammer, Jeffrey S. 1997. "Economic Analysis for Health Projects." World Bank Research Observer $12(1): 47-71$.

Hausman, J. A., Jason Abrevaya, and F. M. Scott-Morton. 1998. "Misclassification of the Dependent Variable in a Discrete-Response Setting." Journal of Econometrics 87 (2): 239-69.

Hawley, William A., Penelope A. Phillips-Howard, Feiko O. ter Kuile, Dianne J. Terlouw, John M. Vulule, Maurice Ombok, Bernard L. Nahlen, et al. 2003. "Community-Wide Effects of PermethrinTreated Bed Nets on Child Mortality and Malaria Morbidity in Western Kenya." American Journal of Tropical Medicine and Hygiene 68 (4S): S121-27.

Hong, Sok Chul. 2007a. "The Burden of Early Exposure to Malaria in the United States, 1850-1860: Malnutrition and Immune Disorders." Journal of Economic History 67 (4): 1001-35.

Hong, Sok Chul. 2007b. "A Longitudinal Analysis of the Burden of Malaria on Health and Economic Productivity: The American Case.” Unpublished.

Killeen, Gerry F., Tom A. Smith, Heather M. Ferguson, Hassan Mshinda, Salim Abdulla, Christian Lengeler, and Steven P. Kachur. 2007. "Preventing Childhood Malaria in Africa by Protecting Adults from Mosquitoes with Insecticide-Treated Nets." PLoS Medicine 4 (7).

Kitchens, Carl. 2013. “A Dam Problem: TVA's Fight Against Malaria 1926-1951.” Journal of Economic History 73 (3): 694-724.

Korenromp, Eline. 2005. Malaria Incidence Estimates at Country Level for the Year 2004: Proposed Estimates and Draft Report. World Health Organization, Geneva, Switzerland.

Kremer, Michael, and Edward Miguel. 2007. "The Illusion of Sustainability." Quarterly Journal of Economics 122 (3): 1007-65.

Kremer, Michael, Edward Miguel, Sendhil Mullainathan, Clair Null, and Alix Peterson Zwane. 2009. “Making Water Safe: Price, Persuasion, Peers, Promoters, or Product Design?" Unpublished.

Kroeger, Axel, Martha González, and José Ordóñez González. 1999. "Insecticide-Treated Materials for Malaria Control in Latin America: To Use or Not to Use?" Transactions of the Royal Society of Tropical Medicine and Hygiene 93 (6): 565-70.

Kumar, Ashwani, Neena Valecha, Tanu Jain, and Aditya P. Dash. 2007. "Burden of Malaria in India: Retrospective and Prospective View." American Journal of Tropical Medicine and Hygiene 77 (6S): S69-78.

Laishram, Dolie, Patrick L. Sutton, Nutan Nanda, Vijay L. Sharma, Ranbir C. Sobti, Jane M. Carlton, and Hema Joshi. 2012. "The Complexities of Malaria Disease Manifestations with a Focus on Asymptomatic Malaria." Malaria Journal 11 (1): 29.

Lengeler, Christian. 2004. "Insecticide-Treated Bed Nets and Curtains for Preventing Malaria." Cochrane Database of Systematic Reviews (2): Art. No.: CD000363. DOI: 10.1002/14651858. CD000363.pub2. 
Lucas, Adrienne M. 2010. "Malaria Eradication and Educational Attainment: Evidence from Paraguay and Sri Lanka." American Economic Journal: Applied Economics 2 (2): 46-71.

Malaney, Pia, Andrew Spielman, and Jeffrey Sachs. 2004. "The Malaria Gap." American Journal of Tropical Medicine and Hygiene 71 (2S): S141-46.

McMorrow, M. L., M. Aidoo, and S. P. Kachur. 2011. "Malaria Rapid Diagnostic Tests in Elimination Settings: Can They Find the Last Parasite?" Clinical Microbiology and Infection 17 (11): 1624-31.

Ross, Amanda, Nicolas Maire, Louis Molineaux, and Thomas Smith. 2006. "An Epidemiologic Model of Severe Morbidity and Mortality Caused by Plasmodium Falciparum." American Journal of Tropical Medicine and Hygiene 75 (2S): S63-73.

-Sachs, Jeffrey, and Pia Malaney. 2002. "The Economic and Social Burden of Malaria." Nature 415 (6872): 680-85.

Sahu, S. S., P. Jambulingam, T. Vijayakumar, S. Subramanian, and M. Kalyanasundaram. 2003. "Impact of Alphacypermethrin Treated Bed Nets on Malaria in Villages of Malkangiri District, Orissa, India." Acta Tropica 89 (1): 55-66.

-Sarriot, Eric G., Eric A. Swedberg, and James G. Ricca. 2011. "Pro-Sustainability Choices and Child Deaths Averted: From Project Experience to Investment Strategy." Health Policy and Planning 26 (3): 187-98.

-Sharma, Surya K., Prajesh K. Tyagi, Khageswar Padhan, Ashok K. Upadhyay, Mohammed A. Haque, Nutan Nanda, Hema Joshi, et al. 2006. "Epidemiology of Malaria Transmission in Forest and Plain Ecotype Villages in Sundargarh District, Orissa, India." Transactions of the Royal Society of Tropical Medicine and Hygiene 100 (10): 917-25.

Smith, Meaghan. 2010. "The Importance of Sustainability in International Public Health NGOs." In Igniting the Power of Community, edited by Paul A. Gaist, 25-37. New York: Springer.

-Snow, Robert W., Carlos A. Guerra, Abdisalan M. Noor, Hla Y. Myint, and Simon I. Hay. 2005. "The Global Distribution of Clinical Episodes of Plasmodium Falciparum Malaria." Nature 434 (7030): 214-17.

Strauss, John, and Duncan Thomas. 1998. "Health, Nutrition, and Economic Development." Journal of Economic Literature 36 (2): 766-817.

Tarozzi, Alessandro, Aprajit Mahajan, Brian Blackburn, Dan Kopf, Lakshmi Krishnan, and Joanne Yoong. 2011. "Micro-Loans, Insecticide-Treated Bednets and Malaria: Evidence from a Randomized Controlled Trial in Orissa (India)." http://www.econ.upf.edu/ TarozziEtA12011RCT.pdf (accessed April 16, 2014).

Tarozzi, Alessandro, Aprajit Mahajan, Brian Blackburn, Dan Kopf, Lakshmi Krishnan, and Joanne Yoong. 2014. "Micro-Loans, Insecticide-Treated Bednets, and Malaria: Evidence from a Randomized Controlled Trial in Orissa, India: Dataset." American Economic Review. http://dx.doi. org/10.1257/aer.104.7.1909.

ter Kuile, Feiko O., Dianne J. Terlouw, Simon K. Kariuki, Penelope A. Phillips-Howard, Lisa B. Mirel, William A. Hawley, Jennifer F. Friedman, et al. 2003. "Impact of Permethrin-Treated Bed Nets on Malaria, Anemia, and Growth in Infants in an Area of Intense Perennial Malaria Transmission in Western Kenya." American Journal of Tropical Medicine and Hygiene 68 (4S): S68-77.

Thomas, Duncan, Elizabeth Frankenberg, Jed Friedman, Jean-Pierre Habicht, Mohammed Hakimi, Nicholas Ingwersen, Jaswadi, et al. 2006. "Causal Effect of Health on Labor Market Outcomes: Experimental Evidence." Unpublished.

Vinetz, Joseph M., and Robert H. Gilman. 2002. "Asymptomatic Plasmodium Parasitemia and the Ecology of Malaria Transmission." American Journal of Tropical Medicine and Hygiene 66 (6): 639-40.

White, Nicholas J. 2009. "Malaria.” In Manson's Tropical Diseases. 22nd ed., edited by Gordon C. Cook and Alimuddin I. Zumla, 1201-1300. London: Saunders Elsevier.

World Health Organization. 2001. Report of the Fifth WHOPES Working Group Meeting: Review of Olyset Nets and Bifenthrin 10\%WP, 30-31 October 2001. World Health Organization, Geneva.

World Health Organization. 2007. Global Malaria Programme: Insecticide-Treated Mosquito Nets: A WHO Position Statement. World Health Organization. 


\section{This article has been cited by:}

1. Benjamin A. Olken. 2015. Promises and Perils of Pre-Analysis Plans. Journal of Economic Perspectives 29:3, 61-80. [Abstract] [View PDF article] [PDF with links]

2. Jessica Cohen, Pascaline Dupas, Simone Schaner. 2015. Price Subsidies, Diagnostic Tests, and Targeting of Malaria Treatment: Evidence from a Randomized Controlled Trial. American Economic Review 105:2, 609-645. [Abstract] [View PDF article] [PDF with links] 